\title{
Queer Eye for the Private Eye Investigating Normative and Counter-discursive Representations in Anthony Bidulka's Russell Quant Mystery Series
}

\author{
A thesis submitted to the Faculty of Graduate Studies and Research \\ in partial fulfillment of the requirements for the \\ Degree of Master of Arts \\ in Canadian Studies
}

\author{
Carleton University \\ Ottawa, Ontario, Canada \\ (C) 2008 by Péter Tracy Balogh \\ Canadian Studies \\ September 17, 2008
}




$\begin{array}{ll}\begin{array}{l}\text { Library and } \\ \text { Archives Canada }\end{array} & \begin{array}{l}\text { Bibliothèque et } \\ \text { Archives Canada }\end{array} \\ \begin{array}{l}\text { Published Heritage } \\ \text { Branch }\end{array} & \begin{array}{l}\text { Direction du } \\ \text { Patrimoine de l'édition }\end{array} \\ \begin{array}{l}\text { 395 Wellington Street } \\ \text { Ottawa ON K1A 0N4 } \\ \text { Canada }\end{array} & \begin{array}{l}\text { 395, rue Wellington } \\ \text { Ottawa ON K1A 0N4 } \\ \text { Canada }\end{array}\end{array}$

Your file Votre référence ISBN: 978-0-494-43444-4 Ourfile Notre référence ISBN: 978-0-494-43444-4

NOTICE:

The author has granted a nonexclusive license allowing Library and Archives Canada to reproduce, publish, archive, preserve, conserve, communicate to the public by telecommunication or on the Internet, loan, distribute and sell theses worldwide, for commercial or noncommercial purposes, in microform, paper, electronic and/or any other formats.

The author retains copyright ownership and moral rights in this thesis. Neither the thesis nor substantial extracts from it may be printed or otherwise reproduced without the author's permission.
AVIS:

L'auteur a accordé une licence non exclusive permettant à la Bibliothèque et Archives Canada de reproduire, publier, archiver, sauvegarder, conserver, transmettre au public par télécommunication ou par l'Internet, prêter, distribuer et vendre des thèses partout dans le monde, à des fins commerciales ou autres, sur support microforme, papier, électronique et/ou autres formats.

L'auteur conserve la propriété du droit d'auteur et des droits moraux qui protège cette thèse. $\mathrm{Ni}$ la thèse ni des extraits substantiels de celle-ci ne doivent être imprimés ou autrement reproduits sans son autorisation.
In compliance with the Canadian Privacy Act some supporting forms may have been removed from this thesis.

While these forms may be included in the document page count, their removal does not represent any loss of content from the thesis.
Conformément à la loi canadienne sur la protection de la vie privée, quelques formulaires secondaires ont été enlevés de cette thèse.

Bien que ces formulaires aient inclus dans la pagination, il n'y aura aucun contenu manquant.

\section{Canada}




\begin{abstract}
"Queer Eye for the Private Eye" is a study of Anthony Bidulka's Russell Quant Mystery Series. This series of five detective novels featuring gay private eye Russell Quant from Saskatoon is the first of its kind in Canadian literature. While considering the origins and evolution of the traditional hard-boiled detective subgenre, as well as recent gay detective fiction produced by authors in the United States, this study explores how lesbians and gays are represented in Anthony Bidulka's imagined community and how a queer reading of the Russell Quant Mystery Series can assist in an interrogation of the relationship between Bidulka's fictional representation and the tensions in the evolving gay community in Canada today.
\end{abstract}

This study analyzes the representation of masculinity, femininity, class, and race in the novels in order to demonstrate how the series is both anti-discursive and normative. While Bidulka's writing effects an initial queering of the detective fiction genre, it represents a site of struggle between contested forms of masculinity and reflects racial and class tensions that are experienced in the gay community today. Bidulka's portrayal of Russell Quant's community helps to make lesbian and gay identities more plainly visible and legitimate, yet the novels also work as agents of "homonormativity," revealing the ambiguity of the author's project, which while aligned with the gay community, participates in affirming dominant heteronormative discourses. I ask how far this new visibility and legitimization of gay culture carried out by the Russell Quant Mystery Series actually goes towards a queering of the genre and what the costs of Bidulka's normalizing project might be. 


\section{Acknowledgements}

Thanks to Professors Jodie Medd, Brian Johnson, Pauline Rankin, Peter Hodgins, and Patricia Gentile.

Thanks to Catherine Jenkins for editorial support, encouragement, persistence, and patience. Thank you, most of all, for believing in me.

Thanks to the management of Environment Canada for flexibility and allowing me to dedicate my time to this project.

Thanks to David Rimmer for inspiring chats and helpful book suggestions.

Thanks to Robert Oates and Cecil Somerton for nourishment and friendship.

Thanks to $\mathrm{LiLi}$ for enforcing routines and rest periods, long walks in all types of weather, and consistent dogness. 


\section{Table of Contents}

Introduction.............................................................1

Chapter One................................................................14

Chapter Two.................................................................32

Chapter Three............................................................64

Chapter Four.............................................................97

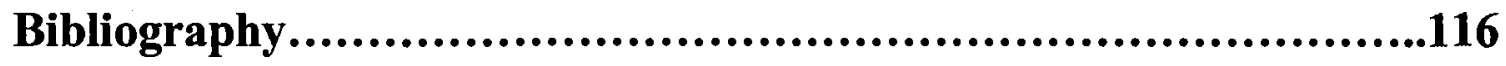




\section{Introduction:}

\section{Queer Eye for the Private Eye}

The Saskatoon Yellow Pages reveal only a handful of investigators for hire. Is it a matter of less population equals less crime, or is Canada simply a less PI-oriented country?

(Amuse Bouche 33)

Over the last thirty years, gay ${ }^{1}$ crime writers have created an established body of work, one that often, although certainly not always, has challenged the limits of traditional detective fiction. And while gay detective fiction is not readily available in most mainstream bookshops, it fills bookshelf after bookshelf in lesbian and gay bookstores across North America—so much so that gay detective fiction is sometimes considered its own subgenre. More curious, then, is the fact that until a mere five years ago, while there existed for more than a decade a number of lesbian and feminist crime writers in Canada, there was seemingly no interest in the genre for gay Canadian authors or readers: "Enter Russell Quant—cute, gay and a rookie private detective" (Amuse Bouche cover notes). Finally, in 2003, with the publication of Anthony Bidulka's Amuse Bouche, Canada's gay private eye had come out—and he is a first-generation Canadian with Ukrainian and Irish heritage living in Saskatoon. By October 2007, Bidulka had published Sundowner Ubuntu, his fifth novel and the most recent in what has become the first successful gay detective mystery series to be written by a gay male Canadian author and published by a Canadian press. Accordingly, something queer is afoot on the

\footnotetext{
${ }^{1}$ Throughout this paper, I use the term "gay" mainly to signify gay men. Accordingly, where I refer to the "gay community," I am referring to a community of gay men. When both lesbians and gay men are referenced, I use the term "lesbian and gay" or "lesbian and gay community." As a self-identified queer person, I chiefly use the term "queer" in reference to lesbian, gay, bisexual, transgender, two-spirited, allied and other people who undertake conscious strategies of resistance against hetero- and homonormativity.
} 
Canadian popular fiction scene-and by way of helping to fill the void of scholarship in this area of Canadian popular fiction I would like to acknowledge this queerness. Therefore, my study takes as its focus queer crime fiction in general and Anthony Bidulka's writing in particular. I ask how far this new visibility and legitimization of gay and lesbian culture carried out by the Russell Quant Mystery Series actually goes towards a queering of the genre and what the costs of Bidulka's project might be.

Through his detective mystery series, Anthony Bidulka has arguably shifted the iconic concept of the tough-skinned, conventionally masculine identity of the American hard-boiled urban crime-fighting hero to a marginal, Canadian landscape, where subversion, self-doubt, and humour appear to reign: a landscape where the only straight line is the horizon. It can be demonstrated that through his creation of gay detective Russell Quant, Anthony Bidulka has gone a certain distance in queering the detective fiction genre. Moreover, by using Saskatoon, Saskatchewan, as Quant's home base, Bidulka places queers in fictional representations of the Prairies, and offers a "Canadian approach" to a genre that has heretofore been dominated by American and British writers. Indeed, through their introduction of a gay private eye living and working in the lesbian and gay community in Saskatoon, the narratives in this series also attempt to transcend the traditional marginalization of others within the genre in a manner that reflects the increasing diversity of Canadian society. And yet the works remain marginalized in that their crossover to the mainstream is limited: the novels are given shelf space primarily in gay and lesbian bookstores.

Such a project as Bidulka's is political and the subjects of his narratives point up tensions that exist in the gay and lesbian community. Yet it can be asserted that Bidulka 
has created a unique space in Canadian culture for the gay private eye. Now, what are the implications of this? Certainly, there exist many American models that could have inspired creation here in Canada. It is possible this Canadian lack is another example of Canadians looking south for culture rather than looking to themselves and creating something nationally specific. If gay (and straight) Canadian audiences are responding to Bidulka's work, is it because they are now looking to see themselves reflected in it and are identifying with the community that Bidulka imagines? How has Russell Quant's successful coming out helped to queer the genre? What does Bidulka's writing say about the gay community in Canada that both consumes and, arguably, serves as the model of community in his novels?

In this thesis, I seek to answer the following primary question: How are Canadian gays and lesbians represented in Anthony Bidulka's imagined community and how can a queer reading of the Russell Quant mystery series help us to interrogate the relationship between Bidulka's fictional representation and the tensions in our evolving lesbian and gay community in Canada today?

Bidulka's novels do not simply inject aspects of gay and lesbian issues and themes into a landscape dominated by heterosexuals. Rather, the narratives help to queer the genre to the extent that they tell stories from within a community where the overwhelming number of characters, themes, and cultural references are gay. At the same time, Bidulka's portrayal of Russell Quant's private-eye investigations in Saskatoon helps to normalize lesbian and gay identities in Canada. Normalization, however, is a project fraught with its own tensions. While Bidulka's work does begin to queer the genre and his fictional landscape, the author is limited by his own gay male subjectivity 
and the mainstream gay community's preoccupations and gender anxieties. In order to represent one community as worthy of acceptance and equal rights, there is a tendency to mainstream those attributes that correspond most clearly to the values of the dominant discourse while further marginalizing and oppressing the 'other' within the same community. Consequently, as I demonstrate, Bidulka is reliant on stereotypes of gays and lesbians, gender, race, and class. His narratives value the attributes of white, masculine, straight-acting, affluent gay men at the expense of the diverse voices that do indeed make up the so-called Canadian rainbow community. I contend, therefore, that while Bidulka's narratives explore certain preoccupations of the mainstream gay community, such as same-sex marriage and homophobia, his portrayal of gay and lesbian identities and issues is reflective of his privileged subjectivity and that of the mainstream gay community in Canada today. In other words, it has its silences. As I demonstrate, the normalization of gay and lesbian culture in Bidulka's fiction compels queer-inspired readings to elucidate the elisions that his texts create in their particular representation and interrogation of the gay community. I explore, thus, how the Russell Quant Mystery Series can be read as primarily lending support to heteronormative power relations, as well as the muted racism, misogyny, and classism that may be found within the gay community.

On the margins, and also central to the primary question, are a number of subproblems that include the following: What broad social and cultural issues can be seen to have influenced the representation of gays and lesbians in Anthony Bidulka's writing? How can we theorize the gay subjectivity of the author, his fictional characters (primarily Russell Quant), and Bidulka's gay audience? And, what roles might subjectivity play in the creation of this series? 
Gay and lesbian crime writing has developed and evolved significantly over the last three decades, and it has made an impact on the genre itself by challenging and changing the limits of the formula and its particular characteristics. The rise of gay and lesbian crime fiction, like the emergence and development of a so-called gay literature and gay culture itself can be seen to have followed the course of gay liberation movements in the West. Prior to 1969 and the watershed in gay rights initiated by the Stonewall Riots in New York City, the rare gay and lesbian characters that appeared in the crime fiction genre were typically figured as deviant, depraved and deranged outsiders who served to demonstrate further the perversity of the urban underworld and the image of evil against which the hard-boiled private eye fought to triumph. Today, however, there exist hundreds of gay and lesbian crime novels that have brought gay and lesbian life in all of its varieties out into the mainstream. The vast majority of these novels, however, have been produced by American writers and published in the United States. When it comes to Canadian gay and lesbian crime fiction, the body of work is much more limited, indeed; where the gay male detective is concerned, there is less than a handful of writers who have explored the genre with any measurable success to date.

I first encountered gay and lesbian crime fiction two years ago, having had no previous experience reading mystery or crime fiction gay or otherwise. I visited the one and only bookstore devoted to queer culture in the city of Ottawa, After Stonewall, and asked the shop owner somewhat tongue-in-cheek if there were any Canadian gay detective novels. I quickly learned that while a number of Canadian feminist and lesbian detective novels published over the course of the previous decade were popular with 
women mystery readers, the only known gay male writer of Canadian gay detective fiction was Anthony Bidulka.

My response could be called typically Canadian: I was both surprised that gay Canadian crime fiction actually existed and not surprised - albeit disappointed - that there was only one gay male author producing it. Now, wherever I have spoken about my research, people tend to react very similarly to the way I did that day. First, they admit never having considered that there would be Canadian gay detective fiction. Next, they claim little surprise at the fact that there is such a dearth of it. Of course, this is the reason for the epigraph to this introduction. In the first novel of the series, private eye Russell Quant muses about the reasons for the limited number of private investigators operating in Saskatoon. I take his rumination as a surreptitious comment about the state of gay crime writing in particular, and perhaps gay writing in general, in Canada today. We're not only not producing very much, we don't seem to be valuing it and exploring it to see what it says about us as a community and as a nation. For indeed, who considers that there are actually Canadian detective novels, let alone gay ones, and that as cultural artifacts they might have much to say about the communities the authors imagine and the communities that see themselves reflected in those works?

In her essay entitled "Murder Ink: Detective Fiction in Canada," Priscilla L. Walton makes similar comments regarding the state of detective fiction writing in Canada through a similar observation about how customers in an Ottawa bookstore were shocked to learn that there are actually Canadian authors writing mystery novels. Not only is there a lack of awareness in Canada of Canadian authors, Walton observes, but more importantly, perhaps, it appears that "Canadianicity is erased from histories of crime 
fiction, an erasure that results in a public largely unfamiliar with Canadian interventions into this genre" (50). In this thesis, I take this lack as my cue, and make it the axis around which my research turns. There is an acknowledged lack of gay Canadian crime fiction and there is also a lack of Canadian scholarship in the domain of crime fiction overall. Moreover, scholarship in Canada and abroad tends to fall into one of two specific areas: concentrated studies of the hard-boiled detective and explorations of the increasing popularity of women detectives in popular fiction, televisions series, and films during the last thirty years.

Recent book-length studies of the hard-boiled subgenre include Erin A. Smith's Hard-Boiled: Working-Class Readers and the Pulp Magazines and Christopher Breu's Hard-boiled Masculinities. In her innovative examination of both popular narratives and advertising, Smith explores the production and dissemination of pulp fiction in the "classic" period of the hard-boiled genre. She demonstrates how hard-boiled detective fiction acted as a means for its working-class male readers to accept the establishment of consumer culture, the evolution of work, and the accompanying perceived threats to their masculinity. Breu undertakes a psychoanalytic and Marxist-based reading of gender, race, and class as cultural fantasies in some of the classic hard-boiled texts. Both Smith's and Breu's studies have been helpful in grounding my analysis of Bidulka's work.

There are three recent, important, book-length studies of women's crime fiction, including feminist and lesbian writing, the first of which is Sally R. Munt's 1994 study, entitled Murder by the Book: Feminism and the Crime Novel. While Munt's book traces the development and significance of women writing crime fiction in Britain and in the United States, there is hardly a mention of Canadian work. Detective Agency: Women 
Rewriting the Hard-Boiled Tradition, published by Canadian academics Priscilla L. Walton and Manina Jones in 1999, moved beyond Munt's study, read newer work, including television series and films featuring women detectives, and analyzed the impact of women's crime fiction not only on the genre but in relation to popular culture and the reading audience itself. Linda Mizejewski's 2004 book, entitled Hardboiled and High Heeled: The Woman Detective in Popular Culture, continues work begun by Walton and Jones. Mizejewski focuses on the popularity of bestselling authors Sue Grafton and Patricia Cornwell, as well as the continuing significance of women detectives in film and television. Accordingly, the present study is indebted, as well, to the concepts elucidated by these academics. To date, Munt's, as well as Walton and Jones's work remains most influential in the domain of women's crime fiction.

In 2004, Judith A. Markowitz produced a unique survey of gay and lesbian detective fiction, including both individual novels and series published since 1964. The Gay Detective Novel filled a great void by providing a summary of themes, plots and characters, a number of author interviews, and a listing of works and authors. It is an indispensable guide for scholars interested in the domain and has helped shape this study. In 2005, Drewey Wayne Gunn also published a survey of detective fiction. As its title suggests, The Gay Male Sleuth in Print and Film: A History and Annotated Bibliography, has a narrower focus than Markowitz's work in that it focuses exclusively on gay male detectives. While it also references film, Gunn's bibliography does not have the depth and breadth of Markowitz's survey.

Little work has been carried out on the impact of gay crime fiction, however, let alone critical analyses of the significance of gay and lesbian crime fiction as regards 
Canadian writing and Canadian audiences. Most of the work produced to date has in fact been celebratory of gay and lesbian crime writing and, like Munt's study, endeavoured to point out its progressive constituents, such as its indictment of society as a primary cause of criminality. Although numerous reviews of Bidulka's novels have been published in the gay press and in some Canadian book review periodicals, this paper represents the first critical analysis of Bidulka's overall work. By introducing the work of Jeffrey Escoffier on the normalization of gays and lesbians and Lisa Duggan's concept of "homonormativity," my study represents a divergence from previous work which emphasizes the progressive nature of gay and lesbian crime writing to offer a more critically queer-inspired look that points to the possible costs of a normalizing project such as that represented by Bidulka's writing.

As a queer-identified individual, I am concerned by the power relations regulating community and the marginalization of difference that community formation and maintenance often entails. I am particularly interested in the marginalization of popular cultural products, such as the genre novel, in the creation of literary products representative of a community. I see these issues as not unrelated and explore them in my analysis of Bidulka's work.

In Chapter One, I lay the groundwork for the analyses that I undertake in the following chapters. Accordingly, I set out a brief history of the detective fiction genre, and explore several arguments regarding how the emergence and evolution of the genre can be theorized. This includes a short review of the hard-boiled subgenre and how it is understood to contest the traditional ratiocinative form. I then undertake a short discussion of some of the most noteworthy (American) gay detective novelists of the last 
four decades, to reveal the major ways they have initiated a queering of the genre. This will help to situate Bidulka's Russell Quant Mystery Series within the history and current context of the genre.

In Chapter Two, I undertake initial readings of Bidulka's texts that seek neither to celebrate queer culture in Canada, nor to suggest that his representation of gay and lesbian identities therein is unproblematic. I first explore in detail how Bidulka represents and manages various gay (and straight) masculinities through the primary character of Russell Quant and his male associates in the novels. This then informs my subsequent analysis of how Bidulka both adheres to the hard-boiled detective formula and at the same time undertakes a certain queering of the American tradition of detective fiction writing. I then examine the overarching theme of homophobia and how it influences the issues of criminality that Bidulka explores in the novels.

In Chapter Three, I investigate how reading Bidulka's fictional representations of the lesbian and gay community may further interrogate and regulate the marginalization of individuals who are not represented by the dominant white, middle-class, gay male voice. My focus here is gender, race, and class. While I draw upon postcolonial theories, as well as theories of race and class to read these texts, my research will be grounded in both foundational and leading-edge work in constructionist and queer theory. While the term "queer" has often been used as shorthand for "lesbian and gay," as well as a means to avoid the gender specificity of the latter term, "Queer Theory" according to Teresa De Lauretis, who is arguably the first academic to use the term, "was arrived at in the effort to avoid all of these fine distinctions in our discursive protocols, not to adhere to any one of the given terms, not to assume their ideological liabilities, but instead to both 
transgress and transcend them—or at the very least problematize them" (v). Accordingly, my readings invoke an interrogation of heteronormative assumptions and problematize the notions of essentialized gender and racial identities in the novels. I will also take a cue from Rob Cover's significant work in using queer theory to problematize issues of class and stereotyping. Cover notes that while the lesbian and gay community might be at once "reliant on the presentation of a visually unified group of people through recognized stereotyping by fixing a visible body image to a set of ideas, attributes, behaviours or dispositions," stereotypes work negatively through repetitive use to "prescribe behaviours on to the bodies of other lesbian and gay identifying individuals" (81). Cover's work and that of other queer theorists informs my readings to the degree that gay and lesbian and racial stereotypes, as well as the representation of an affluent, male-centric community are supported and resisted in lesbian/gay popular and literary fiction.

In the final chapter, I explore the subjectivity of the author and his fictional hero to suggest ways in which this subjectivity has informed the author's normalizing project and his representations of gender, race, and class. Accordingly, I look to Jeffrey Escoffier's work in theorizing the normalization of lesbians and gays and then explore the extent to which I see these texts lending support to or questioning the process that Lisa Duggan has termed the "new homonormativity," "a politics that does not contest dominant heteronormative assumptions and institutions but upholds and sustains them while promising the possibility of a demobilized gay constituency and a privatized, depoliticized gay culture anchored in domesticity and consumption" (179).

In my exploration of how these Bidulka's texts both interrogate and reproduce contemporary realities in the lesbian and gay community, I illustrate how queer readings 
can help to elucidate the tensions inherent in the representation of this community. Of course, the supposition that there is a lesbian and gay community that we can look to in Canada as a reference point is problematic in and of itself. While dominant media tend to portray a unified lesbian and gay entity, lived experience in the community can suggest otherwise. To wit, in Ian Barnard's introduction to Queer Race, where, among other objectives, he sets out a relational framework for theorizing the racialization of queer, he writes that:

When any marginalized subjectivity (i.e. gayness) becomes the basis for community, it will, in turn, create and enforce marginalizing prioritizations and exclusions. The idea of a/the gay community is conjured up to celebrate deviance in the face of a massive structure of compulsory heterosexuality, but also in order to re-inscribe other relations of domination and to silence diverse queer voices. (4)

As I am very conscious of this, my readings help elucidate the tensions in the meanings of community imagined in and through the texts.

For more than fifty years now writers have been struggling to define what makes Canadian literature "Canadian" and what exactly it can say about who Canadians are. The growth of Canadian nationalism in the 1960s and 1970s corresponded on the other hand to a growth in diversity throughout the nation, for women, immigrants and GLBT individuals and collectivities. Writers and academics alike, in particular Northrop Frye, asked then what it is that Canadian literature says about the Canadian "nation," and sought to answer the over-arching question "Where is here?" (220). As a consequence of the development of lesbian and gay studies in North America, Canadian academics interested in emergent queer theory began to ask similar questions of Canadian literature and the Canadian "nation" from a queer perspective. In 1999, Peter Dickinson reread 
concepts of the nation and sexuality in his study of Canadian literature to answer the question "Where is here?" with "Here is queer" (38).

Through this study, I bring a voice to the seriously under-theorized body of cultural production that is the gay detective novel. By examining Bidulka's texts and exploring the community he imagines, I am also glimpsing representations of the gay community the author himself inhabits. If "here is queer," what can the Russell Quant Mystery Series tell us about the multiple and contested meanings of queer in Canada today? 


\section{Chapter One:}

\section{The Gay Private Eye Comes of Age}

\section{Genre Beginnings}

In this chapter, I undertake a brief historical overview of the development of the detective mystery genre and the evolution of the hard-boiled subgenre. At the same time, I introduce hard-boiled fiction's quasi obsession with issues of masculinity. As I demonstrate in this chapter and later in this thesis, hegemonic masculinity is continually contested by different forms of masculinity as the subgenre evolves.

We can trace the roots of the detective novel back to the early to mid-1800s to newspaper accounts of violent crimes and reprinted confessions of accused criminals. Certainly, stories involving gruesome accounts of crime were as titillating to members of society in the nineteenth century as they are today, while the narratives resulting in the triumph of common good over evil were equally soothing to a civilized society dependent on the restoration of order. With the development of western capitalism, a growing proportion of the population could read and afford to buy such stories; accordingly, appetite for them grew. At the same time, the growth of capitalism necessitated the protection of private wealth, which through the moralization and Christianization of the individual worker, entailed the repudiation and segregation of the criminal from both rich and poor citizens alike, citizens whose wealth, health, and happiness were threatened by criminals. It is this popularization of the moral subject that, according to Michel Foucault "brought to life the first detective stories and the development of the genre" (Power/Knowledge 41). The development of the detective genre, through thousands of 
individual works and a myriad of series repetitively presents a triad of crime, investigation, and resolution. In Foucault's re-interpretation of Bentham's Panopticon, the surveillance of the population becomes individualized through the growth of state institutions and the expansion of surveillance by other members of society. Moreover, for Foucault, panopticism "must be understood as a generalized model of functioning; a way of defining power relations in terms of the everyday life of men" (Discipline and Punish 205). Constant surveillance in society causes individuals to internalize surveillance itself to the point where they learn to automatically police and discipline themselves accordingly. This panoptic view can be applied throughout society and culture. The cultural representations of popular fiction, too, reinforce the "discourse of law" that has helped to create and maintain the modern version of Western society. The strict adherence to formula and the repetitive nature of the detective mystery genre help it to act as a mechanism of self-discipline for its readers.

The generally accepted modernist view of the detective story seems to support Foucault's thesis. More than thirty years ago, Julian Symons argued convincingly in Bloody Murder that Edgar Allen Poe is the 'undisputed father' of the detective story, as the author had been inspired by the memoirs of Eugène François Vidocq, a French criminal turned police inspector who died in Paris in 1857. Poe's fictional detective, C. Auguste Dupin is thought to be based on Vidocq, and his three short stories, beginning with "Murders in the Rue Morgue," published in 1841, arguably constitute the first fictional detective series in English. While Poe is perhaps better known for his Gothic horror tales and his perfection and promulgation of the short story form as a literary commodity, he is generally recognized as the first author to set out the basic conventions 
for what was to become the detective fiction genre. These conventions include the popular detection methods of observation and rational deduction and the use of a foil or side-kick as a second pair of eyes and note-taker, as well as narrative conventions that Howard Haycraft has described in The Art of the Mystery Story as "the first complete if exceedingly awkward use of the least-likely-person theme, the first instance of the scattering of false clues by the real criminal, and the first extortion of confession by means of the psychological third degree" (10).

Indeed, these are among the foundational conventions of the genre, so much so that they remain integral to the form, even through all manner of queering the genre that has occurred in the later years of the twentieth century and in the beginning of the twenty-first. The popularization of this form and its constituent conventions work didactically in that they instruct readers that the delinquent may be among them, may be a member of their own class, is not necessarily overtly criminal in appearance or action, and may be in fact the least likely suspect.

Following Poe's detective stories, the 1887 publication of Arthur Conan Doyle's A Study in Scarlet formally established the detective fiction genre and Doyle's subsequent tales of his character Sherlock Holmes created the fully-rounded archetype of the private detective. Accompanied by his side-kick Watson, Holmes exudes a superior intellect and rationality to the common man. As Christopher Breu reaffirms in HardBoiled Masculinities, discourses of masculinity in the nineteenth century "were predicated on a Victorian conception of "civilization" that emphasized physical restraint and conscious sexual renunciation" (6). This representation of intellectuality and morality as masculine ideals for middle-class white men corresponds to the Foucaultian view of 
the civilizing projects of capitalism and the protection of wealth. With Doyle's

production of Sherlock Holmes, the ratiocinative detective story became the classical armchair whodunit that would continue to be repeated well into the twentieth century and form the basis of the Golden Age of detective fiction. The Golden Age is seen commonly as the classic period of whodunits from 1920 to 1937, encompassing all of the works of Agatha Christie and Dorothy L. Sayers and their contemporaries. A majority of the authors that comprise this canon are British, but the canon includes Americans Ellery Queen (a writing duo comprised of Frederic Dannay and Manfred Bennington Lee), Rex Stout and John Dickinson Carr who maintained the classic form.

In his chapter on detective fiction in Uncommon Cultures: Popular Culture and Post-Modernism, Jim Collins makes a salient observation in response to the Foucaultian view of the development of the detective story:

A panoptic subordination of everything to one centralized power fails to explain the existence of the detective in the first place. If the State is indeed a Panopticon, the independent investigator is not necessary, except perhaps as an occasional hired hand for the state police force - a role very seldom adopted in the history of detective fiction. (30)

Collins contends that Foucault's concept of the State as a Panopticon is monolithic and that it cannot account for lateral power relations and the "visibility of discursive alternatives" that, arguably, the detective, and more so, the emergent private eye must represent. The detective novel presupposes alternative means for achieving justice, and is often a critique of State-endorsed justice that is taken for granted in more normative forms of the genre like the police procedural. Indeed, contemporary detective fiction is often very critical of the society in which it operates. Foucault's ideas are not to be discounted, however. On the contrary, it is this tension between the private eye as 
representative of Foucaultian "common sense" and contemporary discourses of law and order and, at the same time, representative of an alternative way of being and acting in the world that makes theorizing detective fiction so contentious and ideologically complex. Furthermore, while issues of criminality and the restitution of order form the basis for the narratives in detective fiction, the social contestations and accompanying tensions presented by the private eye are not restricted to issues of criminality and justice. Towards the end of the Golden Age of detective fiction, in the United States, the emergence of the Black Mask and other detective pulp magazines in which the first hardboiled detective fiction was published further supports Collins's thesis. Other contemporary investigators of detective fiction point to the nature of American life and contradictory discourses of masculinity in challenging and reshaping the original format of detective fiction. Sally R. Munt posits in Murder by the Book, that "in the diverse and entrepreneurial USA, the spirit of individual achievement rendered the class-bound British country-house murder inappropriate" (2). Moreover, as Christopher Breu points out, the cultural ideals with respect to masculinity continued to change at the beginning of the new century, "moving from the older discourse of manliness to a newer celebration of an active, exteriorized, and more violent conception of masculinity, one that was associated more readily with working-class men" (Hard-boiled Masculinities 6).

One of the most studied of the formative hard-boiled detective fiction writers is Dashiell Hammett, who, with the publication of Red Harvest in 1929, imagined a new breed of detective. This is the private eye who walks to the beat of his own moral code. Hammett's hero, the Continental Op, expresses most clearly the active agency that Breu refers to as germane to the newer discourses of masculinity embraced by the hard-boiled 
dick. In negotiating his terms with his client in Red Harvest, the Continental Op declares: "I'd have to have a free hand—no favours to anybody—run the job as I pleased" (44). Working on the edge of or outside the social order, often without the police if not clearly against them, he is a lone crusader pitted against the evil and chaos of the urban landscape. It has been suggested by a number of theorists, including Catherine Jenkins in "The Hardboiled Outsider," a study of the hard-boiled subgenre as an existential literature that the hard-boiled detective may have evolved out of the stories about the outlaw heroes of the American Wild West. Introduced in the early 1800 s, the QuickDraw-McGraw type of anti-hero evolved in a lawless wilderness, where the lone white male settler stood alone to battle the "evil" indigenous other. The major difference between the two anti-heroes is a shift from rural to urban (139). It is not that difficult to see that in both cases, nonetheless, the hero can be seen to represent Foucault's moralizing and Christianizing civility that is threatened by the "lawless" Native others in the Wild West and by corrupt, fallen denizens and lawmakers of the city, who have fallen prey to the evil of human greed. Although he performs his role with violence rather than intellect and ratiocinative deduction, the Wild West outlaw anticipates the hard-boiled anti-hero and both recall the petit-bourgeois detective of the Golden Age in their installation or restoration of a white, middle-class social order that protects the privileges of civilized society. Accordingly, from the 1920s to the 1950s, hard-boiled subgenre, arguably dominated by American writers, took as its principal hero this hard-hitting, smart and sexy, exclusively heterosexual, hyper-masculine, male private eye modeled on the likes of Hammett's literary icons Sam Spade and the Continental Op. 
Readers of hard-boiled detective fiction learn repeatedly to valorize the attributes of conventional masculinity as performed by the detective heroes. In Red Harvest, Elihu Willsson hires the Continental Op to sanitize his city of its rampant corruption with this warning: "It's a man's job. Are you a man?" (42) This does not, however, mean that there are no representations of masculinity other than hegemonic masculinity in the hard-boiled subgenre. Men coded as homosexuals, fairies, and queers are present in detective stories even early on in the development of the subgenre. In Hammett's The Maltese Falcon, for example, the character of Joel Cairo oozes with queerness:

Mr. Joel Cairo was a small-boned dark man of medium height. His hair was black and smooth and very glossy. His features were Levantine. A square-cut ruby, its sides paralleled by four baguette diamonds, gleamed against the deep green of his cravat ... He held a black derby hat in a chamois-gloved hand and came towards Spade with short, mincing, bobbing steps ... He sat down primly, crossing his ankles, placing his hat on his knees, and began to draw off his yellow gloves. (43)

Like Cairo, the fairy was often distinguished as queer by exaggeratedly feminine characteristics and an attention to excessively colourful and bejewelled clothing. Moreover, as is the case with Cairo, the fairy was often doubly marginalized by virtue of his ethnicity or race. This is a tendency which continues even today in stereotypical characterizations in some detective fiction. Men like Cairo and the homosexual Carol Lundgren in Raymond Chandler's The Big Sleep are often associated with corruption and sleaze and they are always made to pay for their sin of being queer: they go to jail or they are killed off and go to an early grave.

While Dashiell Hammett and Raymond Chandler are often cited as the most well known and influential of the early hard-boiled writers, the line of influence notably continues through the work of Ross Macdonald to Mickey Spillane. In the period following the Second World War, the thriller mystery developed out of the hard-boiled 
detective mystery. Thriller mysteries, written by authors such as Jim Thompson and James M. Caine, saw the disappearance of the private eye such that the anti-hero was replaced by a criminal or any type of average man.

While the traditional or ratiocinative subgenre of detective fiction continues to be produced, the hard-boiled subgenre has had a lasting effect on what is written and published today. Indeed, while much contemporary detective fiction falls within the overall formula, much of the fiction published today in the women's, lesbian, and gay subgenres takes its cue from the hard-boiled detective novel.

\section{The Gay Dick Comes Out}

Beginning in the 1970s and 1980s, Americans Joseph Hansen and Richard Stevenson effectively turned the crime fiction genre on its head with their respective gay detective series. Since then, dozens of authors, including most notably Michael Nava and Mark Richard Zubro have expanded on gay themes in their novels, at the same time chronicling the evolution of gay America. Today there are countless examples of the gay detective novel in the United States, and several very well known series which are read throughout the English-speaking world.

Certainly, the mere coming-out of the private eye and the treatment of gay themes have queered the detective fiction genre to a certain degree. Moreover, since the creation of the first gay private eye some forty years ago, successive detective stories and series have helped to queer the genre further, effectively creating a subgenre of gay detective fiction. This is because a succession of gay writers have reshaped and challenged the traditional hard-boiled model not only through gay characters and themes, but by 
radically altering its format and style, by representing alternatives to traditional, tough guy masculinity and by further politicizing issues of criminality, as well as gender, race and class. There are several theories regarding why crime writing has become so popular for lesbian and gay authors and readers alike. In her exploration of the connection between the hard-boiled subgenre and existentialism, Jenkins affirms that the similarities between the two include "the centrality of the subject, the problematic nature of the relation between the I and the other," and the importance of the role of morality (121). These issues are arguably significant factors in how many lesbians and gays, as outsiders, come to define themselves within society. It is also possible that the rigid hegemonic formula is intrinsically fun to subvert; that feminist writers have enjoyed inverting the patriarchal order inherent in the traditional hard-boiled; that gay writers can play with the representation of alternative masculinities: detective fiction is, after all, first and foremost about entertainment. And yet, as a form that must reflect the major preoccupations of its day in order to appear as realistic and believable as possible, it is also likely that detective fiction must simply represent, in this marginalized form of literature, the challenges and changes that minority groups are continuing to pose to the dominant heteronormative social system.

A brief review of the history of gay detective writing shows a polarization in the treatment of the hero and his masculinity, for example. On the one hand, some early writers attempted to subvert homophobic tendencies in the genre that saw gays and lesbians characterized mostly as marginal, sexual perverts by presenting the toughshelled, action-hero-like figure of the hard-boiled private eye who just happens to be gay. 
On the other hand, some writers chose to mock the genre, creating campy and outrageous narratives that both enhance and invert gay and lesbian stereotypes.

Joseph Hansen is generally considered to be the trailblazer in gay crime fiction. His middle-aged, insurance claims investigator Dave Brandstetter is the first gay investigator who was modelled on and consequently expanded the archetype of the hardboiled detective. Hansen published his first Dave Brandstetter novel Fadeout in 1970, and surprised crime fiction readers and critics alike by presenting them with a detective who exhibited the traditionally masculine character they expected of a detective but who was at the same time a thoroughly happy and well-adjusted homosexual. In an interview he gave to the Orange County Register in 1998, Hansen observed: "My joke was to take the true hard-boiled character in American fiction tradition and make him homosexual. He was going to be a nice man, a good man, and he was going to do his job well" (August 10, 1998). Hansen's use of the traditional hard-boiled literary style also helped critics take his work seriously. The Dave Brandstetter series is set in southern California and Hansen's writing throughout strikingly evokes the writing style of Raymond Chandler and Ross Macdonald, if not occasionally Hemmingway, with his short, terse phrasing:

Guava Street had no sidewalks. Little enough remained of its paving --- bleached, cracked islands of blacktop that stood inches above the dirt level of the street. The Jaguar rocked and rumbled. Weeds edged the street, seedy, sun-dried. There were a few fences, chainlink, picket, grapestake. The houses, on narrow lots, were similar here, the stucco sometimes broken away, showing chicken wire and tarpaper. Under untrimmed, drooping pepper trees, the composition roofs were losing their green and silver coatings. Rooflines sagged. (Nightwork 25)

Through his use of both hard-boiled style and form, Hansen deftly took this first openly gay private eye out into the mainstream, where he was readily embraced. 
In Fadeout, Brandstetter must uncover the truth about the disappearance of singer Fox Olson. At the close of the novel, Brandstetter clears Olson's secret gay lover Doug Sawyer of Olson's death and ends up falling for Sawyer. In 1970 this novel did indeed invert the detective genre because up until that time homosexuals were consistently portrayed as feminized and racialized "outsiders," perverts who could not be the central agent of the narrative in this iconically masculine genre.

Indeed, at least two authors created gay detectives prior to Hansen in the 1960 s. Lou Rand's Gay Detective in 1961 presented a very effeminate private eye and many stereotypes that may have been intended to poke fun at the genre. George Baxt's Pharoah Love Series about a gay Black cop in New York City who drives a Jaguar and talks jive, surprised and confounded critics at the time of the first novel's release in 1966. Baxt's novels have been equated with high camp, queer hyperbole, and confirming the gay detective to an ex-centric role. Consequently, Baxt's writing has not always been taken seriously and has been under-explored.

Hansen was the first writer of detective fiction to counter in a serious manner the hegemonic representation of the gay outsider as effeminate, monstrous, or mentally ill. Contrary to what would be expected from a social deviant, Brandstetter stakes out the moral high ground in his dedication to uncovering the truth, reflecting Hansen in his desire to normalize homosexuality by giving a realistic visibility to gay and lesbian people in his work. True to hard-boiled form, Hansen did not shy away from sex, alcohol, and moral corruption in his novels, and dealt deftly with significant gay themes of the 1980s, including coming out, homophobia, and AIDS. In addition to creating the first gay yet conventionally masculine investigator, Hansen also endowed Brandstetter with a 
personal life that developed throughout the series. This was also a significant shift from the hard-boiled model that focused on the private eye's investigation and the action of the hero, not his personal story. The new focus in itself may reflect a significant queering of the genre through a subversion of heteronormativity's insistence on strong public and private split within the hard-boiled genre, whereas the process of coming out gay and the formation of a gay subjectivity necessitate a radical break with the closet. Later gay and lesbian detective series, including Bidulka's novels, follow this trend by presenting heroes whose characters and lives become increasing complex as the series progress.

Hansen featured Brandstetter in twelve novels across a span of twenty-one years. With each successive novel, he created an evolving subgenre in detective fiction that subsequent gay writers of crime fiction would build upon and transcend. The Independent observed in 2004 following Hansen's death, "By pioneering a gay hero in a popular fiction genre that, up until he started writing, had generally treated homosexuals as figures of fun or contempt, Hansen did as much as anyone to break down barriers of ignorance and bigotry" (Adrian 2).

Richard Stevenson's series of Don Strachey private-eye novels also spanned more than twenty years, beginning with Death Trick in 1981 and ending with Tongue Tied in 2003. Richardson followed in Hansen's footsteps to a large degree but the style of his novels became less hard-boiled as the series progressed. The hero of the novels, Don Strachey, is a less tough-skinned, rational and righteous investigator than his predecessor Dave Brandstetter. With Don Strachey, we see a much more self-reflexive, self-doubting and emotionally volatile man who exhibits characteristics that are traditionally regarded as feminine. Through his development of the series, therefore, Stevenson's hero evolves 
into a gay man somewhere between the hard-boiled Brandstetter and the characters presented in Baxt's Pharoah Love series. Stevenson also continued the trend of extending the narrative into a robustly developed personal life of the hero, which includes his longterm partner, New York legislative aid Timothy Callahan, and a complete set of family and friends. While Hansen's Dave Brandstetter moved back and forth between straight and gay circles and themes, he was not a fully developed member of the gay community that existed at that time in Los Angeles. Passing as a straight-acting gay man plays an important part in the series and Hansen, in his desire to help normalize the gay man, helped to reinforce the traditional and dominant version of how masculinity should be performed. This is less of an issue in Stevenson's case, as private eye Don Strachey is confined to the gay community and he is called on at the beginning of each novel as much for his investigational expertise as for his knowledge of the gay community in Albany, New York. Stevenson's novels, therefore, present some of the first portrayals of the evolution of a visible gay community in the United States. Coupled with good writing and criminal intrigue these stories apparently make for good television: over the last three years, four of Stevenson's novels have been produced as films for Here!, an American gay and lesbian television network. Accordingly, the novels are seen to have historic value in their recording of gay memory.

Michael Nava's series of detective novels featuring Henry Rios ran from 1986 to 2001. Rios, an alcoholic criminal defense lawyer, broke new hard-boiled detective ground by being the first gay and Hispanic private eye based on the hard-boiled form in American crime fiction. Again, this series did not shy away from the gritty characteristics associated with the hard-boiled subgenre. Nava's willingness to explore contemporary 
issues of significance to gays and gay Chicanos in the 1980s and 1990s, including AIDS, addiction, racism, and homophobia opened the genre to a further interrogation of normative discourses that marginalize and oppress. Rios was not the first author to subvert the racist tendencies of the detective genre. And, while camp can certainly be used subversively, it is the serious, issue-driven hero of Rios's novels that set his writing apart from Baxt's campy parodies of the genre and his racialized cop hero Pharaoh Love. Still writing today, and among the most popular gay crime fiction writers are Mark Richard Zubro and John Morgan Wilson. Zubro continues to produce two series: the Tom and Scott series and the Paul Turner series, which are both bestsellers in the gay community. His writing has continued the contemporary trend in gay detective fiction to position the private investigator as working solely within the gay community. This may be a reflection to some degree of the gradual ghettoization of gay communities within large urban centres over the course of the last four decades. While this attribute could suggest a type of queering of the genre, it also harkens back curiously to the traditional detective story that functioned within a closed setting with a finite number of criminal suspects. Zubro's work also presents a younger and more dynamic and diverse gay community than those that figure in previous works. There is a less overt political activism in these works than in Stevenson's novels about AIDS but issues of criminality raised do involve an element of social critique. This is reflective of the declining state of gay political activism, as well as of the s(co)urges of consumerism and the Hollywooddriven entertainment industry, and the evolving concepts of what it means to be gay and male in North American urban centres today. 
The sole exception to this tendency for writers to produce what many academics and readers term soft-boiled detective fiction is Wilson. The author of seven books in the Benjamin Justice series, Wilson presents a private eye who represents the side of the gay community that mainstream leaders would probably not like the general public to see. Benjamin Justice is a disgraced journalist, a lonely and angry alcoholic with a chip on his shoulder and a passion for gritty sex in grimy locales. The narratives in Wilson's series, which began in the late $1990 \mathrm{~s}$, are issue-driven and focus on the evolution of the main character and his drive to survive. The series does not shy away from controversy: Justice, who is white, became HIV-positive in the third novel as a consequence of rape by a racialized ex-cop. There are many ways that Wilson has transcended contemporary and historical boundaries with his innovative work. The reader is presented with unsettling versions of masculinity, for example, wherein Justice, as symbolized by his name, possesses a new-found deep desire to seek truth and justice, yet at the same time, through ruthless self-loathing and internalized homophobia is unable to face the truth of his own addictions to alcohol and sex. Both tender and violent in character, Justice presents a hyper-masculinity entwined with a penchant for dangerous sex. This characterization is perhaps symptomatic of a crisis regarding masculinity as can be seen in the turn away from traditional attributes of hegemonic masculinity in other contemporary works. At least one academic, Sharon Wheeler, has recognized Wilson's work. She, however, concurs that he is an exception:

The political radicalism and issue-driven books of the likes of Stevenson and Nava, and the searing conscience of Wilson have been elbowed to one side by the birth of the gay cosy. Writers such as Jon P. Bloch, Rick Copp, Dean James and David Stukas have produced books with flighty, cute, gym bunnies; paranoid actors; gossip columnists and vampires as the heroes! (Wheeler 16) 
Wheeler suggests that there is a marginalization of hard and serious gay crime fiction occurring in the genre today, and given what is currently being published she may very well be right. This does not mean, however, that the trend is here to stay.

Bidulka's writing does not fall neatly into the category of the gay cosy, even though he does position his hero Russell Quant as a cute and sexy private eye. In spite of Bidulka's queer sense of humour and occasional flare for camp, which is expressed throughout the series, Bidulka's novels are issue-driven. Moreover, there is a noticeable trend towards heavier and more serious political issues as the series evolves. As I demonstrate in my exploration of issues regarding criminality in the series, Bidulka has not shied away from raising controversial issues and yet he has not created a gay hardboiled outsider of the dark kind that Wilson has with the Benjamin Justice Series.

\section{Gay Detective Fiction in Canada}

Until very recently, there have been no gay male detectives in Canadian crime fiction. There has been an occasional male bisexual detective in Canadian fiction, for example, in the work of Edward O. Phillips of Montreal. Phillips, who won the Arthur Ellis Award ${ }^{2}$ for his novel Buried on Sunday, is best known for his Geoffrey Chadwick novels that present a somewhat cheeky side to the life of a corporate lawyer in Westmount. The novels are not of the hard-boiled style but rather the traditional cozy and although they are well written and present interesting social commentary about a unique slice of urban Canadian life, they fall outside of scope of the current study.

\footnotetext{
${ }^{2}$ Arthur Ellis Awards are presented annually for Canadian works in the crime genre. See the website at: http://www.crimewriterscanada.com/cwc/pages/awards.html
} 
Indeed, for decades, gay readers seeking entertainment via identification with a gay hero sleuthing the crime-riddled streets of the gay ghetto would have to look south to American writers to get their mystery fix. In 2003, this changed when Anthony Bidulka published Amuse Bouche, the first of the five gay detective novels that now comprise the Russell Quant Mystery Series. Bidulka quickly followed the success of his first book with Flight of Aquavit (2004), Tapas on the Ramblas (2005), Stain of the Berry (2007), and the latest novel, Sundowner Ubuntu (2007). More novels are forthcoming; as Bidulka indicated in a interview with Scott Dagestino published in $F a b$ in 2007, a sixth book in the series is to be launched in fall 2009 (25). The audience base for Bidulka's books continues to grow across Canada and the United States, where more than half of the books are sold, and his work continues to find new audiences in Australia and the United Kingdom, as well. To wit, Bidulka is the first male author from Canada to win the Lambda Literary Award ${ }^{3}$ for mystery fiction for the 2005 American release of Flight of Aquavit. The American edition of Stain of the Berry was a finalist for this year's 2008 Lambda Literary Award for mystery fiction. Bidulka's first three novels are successful enough that Insomniac Press has reissued them as mass market paperbacks.

Following Bidulka's initial success with Amuse Bouche, another Canadian writer entered the crime writing scene with a novel featuring a gay detective. In 2004, Garry Ryan published Queen's Park. It features Detective Lane, a gay police officer based in Calgary, Alberta. In 2006, Ryan published the Lucky Elephant Restaurant, which has become the second novel in the Detective Lane Series. According to the author's website, a third novel is to be released in fall 2008. The novels, which also feature Lane's straight

\footnotetext{
${ }^{3}$ The Lambda Literary Foundation offers over 25 awards annually for gay and lesbian writing distributed in the United States. See the website at http://www.lambdaliterary.org/index.html.
} 
police partner, Detective Harper, and Lane's life partner, Arthur, fall into the category of the police procedural. While his novels are not part of the hard-boiled subgenre, it is important to signal that Ryan, who is not gay, has in the last few years added a new dimension to gay detective fiction in Canada which is arguably dominated by Bidulka's Russell Quant Mystery Series.

Accordingly, while something queer is at last afoot in Canadian detective fiction, there is more here to investigate than a story about a gay Canadian writer who has made a unique connection with a gay Canadian readership. As a series of private-eye novels, Bidulka's work is clearly rooted in the hard-boiled subgenre and keeps with many trends that are specific to gay American detective fiction today. At the same time, Bidulka's writing remains normative in terms of its treatment of gender, race, and class. The success of Bidulka's novels may be due to the author's attempt to keep one foot rooted in the traditions of the genre and another foot poised to transcend its current boundaries. It is these tensions that I explore in the next two chapters, beginning in Chapter Two with a discussion of Bidulka's representation of masculinity and whether he may be seen as queering some of the constitutive elements of hard-boiled detective fiction. 


\section{Chapter Two:}

\section{From Masculinities to Criminalities}

She didn't know who to call, so I asked around. Eventually your name came up, and with your being gay and all, I thought it'd be easier for Tanya to deal with you than some macho bull-dick detective.

I'm not macho?

(Stain of the Berry 94)

In the above-cited quotation from Bidulka's fourth novel, Tanya Culinaire's employer Vicky is explaining to Russell Quant how it came about that Tanya contacted him for help just before she suspiciously fell to her death from her apartment balcony. While searching for clues that will hopefully lead him in the direction of a "boogeyman" who has been stalking and terrorizing the members of a Saskatoon gay choir group, Quant also learns a set of discrete clues about his own identity, among them that he is not "macho." It is in fact through this investigation to identify the boogeyman that Quant comes to reveal even more to the reader about his own identity. Although detective fiction ostensibly concerns discovering the identity of a criminal, it is also about discovering the subjectivity of the detective. Sally R. Munt argues that investigation and resolution in the lesbian crime novel occur for the detective though a process of individuation by "coming out" followed by integration into a new community developed throughout the narrative:

The protagonists deal with fear and paranoia through action, by becoming active agents of their own destiny. The formation of identity happens through the solution of a crime. The central narrative device and locus of readerly pleasure is discovery. (Murder by the Book 125) 
Susan Wheeler observes in her essay on John Morgan Wilson that this process of identity formation could be equally applied to many gay crime novels yet she does not develop this idea further (9).

When Vicky tells Quant that he was called upon because he is gay and not "some macho bull-dick detective," his masculinity is immediately threatened and his sense of how he is perceived in the world is cast into doubt. In his unspoken response of "I'm not macho?" Quant uses humour to deflect the acerbic nature of Vicky's comment but it is nonetheless a serious question for Quant and one that is raised throughout the series. Accordingly, I argue that in Bidulka's work this process of discovery turns significantly around issues regarding Quant's masculinity so that the series can be read as a site of contestation between competing forms of normative and counter-discursive masculinities. In this chapter, I begin my exploration of how Bidulka has employed the detective fiction genre to entertain his audience while in effect queering —in a Canadian context—this decidedly masculine and straight American form of writing. Although Bidulka is writing some 70 years after the original pulp writers first produced their hard-boiled detective stories, his project of normalizing the gay community is not unlike their aim to provide a site for managing the working-class struggle to come to terms with a paradigm shift in hegemonic masculinity. Aspects of femininity continue to pose a threat to the private dick, much as they did in the early hard-boiled works. These threats to heteronormative discourses are demonstrated through the ways in which Quant's masculinity is represented and challenged, particularly in relation to the narratives' gay themes and characters, the representation and exploration of place, and the tropes of good and evil, survival and death. 
I first address in some detail Bidulka's representations of Russell Quant's masculinity, as well as those of Quant's male friends in the series, and how these representations help to queer the genre. I then explore further examples of queering by looking at the how issues of masculinity and femininity resurface elsewhere in the novels, in their overall themes, in their exploration of contemporary criminality, and in other elements of the detective formula and style that Bidulka redeploys in this gay Canadian context.

A precise definition of hard-boiled masculinity is difficult to pin down: the pulp fiction writers tended to present he-men whose physical prowess was their significant masculine attribute. In the pulps, this cultural ideal was supported by the advertisements for bodybuilding courses that framed the stories. Subsequently, Hammett and Chandler, two of the hard-boiled genre's most cited authors presented a much more developed hardboiled hero that Christopher Breu characterizes as possessing "a prophylactic toughness that was organized around the rigorous suppression of affect and was mirrored by his detached, laconic utterances and his instrumentalized, seemingly amoral action" (1). This hypermasculinity, which included the ability to strike and kill with little or no emotion, is seen as a response to the perception that society was out of control, institutions were corrupt, and threats to survival lurked everywhere. Erin A. Smith demonstrates how hardboiled detective fiction acted as a means for its working-class male readers to accept the intrusion of consumer culture, the wartime and post-war evolution of work, and the accompanying perceived threats to their manhood. She also exposes the link between the hard-boiled detective's physical prowess and unquestionable manhood and significant shifts in working class economy and consumer culture: 
With their monomaniacal dedication to work, anxiously overdone manliness, obsessive interest in clothing and interiors, and tough-talking machismo, hardboiled private eyes were the perfect salesmen...it remained only for the advertisers to step in with the necessary products. (44)

Smith's thesis is that hard-boiled fiction was used by its working-class male writers and readers to negotiate the tensions caused by threats to traditional masculinity from a feminization of the workforce through the simultaneous decrease of manly work such as skilled manual labour and the increase in women workers. This was also the beginning of a twentieth-century transformation in consumer culture that compelled men to become consumers, a role that was seen as emasculating the masculine role of the producer.

Now, at the beginning of the twenty-first century, this transformation in consumer culture continues and it can be read in contemporary gay detective fiction. In her essay, Sharon Wheeler makes the distinction between radical, issue-driven hard-boiled-based gay private eyes such as Wilson's Benjamin Justice on the one hand and soft-boiled gay detectives such as Michael, Robert and Monette in David Stukas's comedic detective series. The trend towards a decidedly soft-boiled and ultimately cosy turn in gay detective fiction does correspond with the arrival of more positive, if not stereotypical, representations of gays and lesbians on American and Canadian prime-time television shows. Wheeler notes that "it might be argued that shows such as Queer Eye for the Straight Guy have a lot to answer for. While there are positive angles to portraying the unthreatening gay man next door, it runs the risk of reducing them to comedy levels." (16) But there is more at stake here. Although she raises the general question about the influence of Queer Eye, Wheeler fails to ask whether it is the overwhelming success of Queer Eye that is responsible for current trends in representing gay men in other contemporary cultural products such as detective fiction, or if Queer Eye is symptomatic 
of a larger movement that is helping to move the markers. For clearly, although Queer Eye is comedic in the ways it plays off gay stereotypes, what the show is really about is getting people — specifically gay men to whom the show was initially marketed-to buy into a gay brand. After all, as Andil Gosine noted in 2001, "To be gay and male, the story goes, is to fully indulge capitalist consumption" (35). I argue that it is the commodification of gay culture that has produced Queer Eye and other cultural products such as the gay cosy. Of course, not all contemporary detective fiction writers "buy into" this. Wilson's Benjamin Justice is clearly apart from this trend: an aging, disgraced, addicted gay outcast, Justice is driven by his desire to survive. He is not a consumer, but rather he is consumed by his addictions.

The Russell Quant Mystery Series lies somewhere along the spectrum between the gay cosy and Wilson's updated version of the traditional hard-boiled form. Each of Bidulka's novels provides numerous examples of the author's penchant for referencing popular culture, especially gay cultural icons, as well as endowing Russell Quant with a stereotypically gay taste for and desire to consume goods and services in the areas of travel, food and wine, décor, grooming and fashion. And, while introducing gay themes and populating narratives with gay and lesbian people may go some way towards queering the detective genre, it is only part of the story. Theorizing the conjoining aspects of gayness, masculinity, and consumer capitalism can help one read Bidulka's work as the representation of the competing discourses of traditional masculinity and consumer masculinity in the mainstream gay community.

Beginning with the Stonewall Riots of 1969 and most clearly since the onset of the initial North American crisis of AIDS in the 1980s and 1990s, the gay and lesbian 
community has been increasingly commodified. Corporations that continually seek new markets have been quick to seize upon the gay community as an emerging market and the visible mainstream of the white, educated, affluent and able gay man was not slow to take up the offer to buy into a new gay culture that it was assumed he should inhabit and exhibit. An exploration of the origins and evolution of this culture is beyond the scope of this paper and has been studied to some extent ${ }^{4}$, although much more work needs to be done in this area, specifically on its implications for lesbian and gay people beyond the mainstream and for gay cultural productions, including popular fiction.

This commodification may indeed have reached its apex with the arrival of television's Queer Eye for the Straight Guy and its hosts, known as the Fab 5, in 2003. For these self-proclaimed experts of style, queer life was easily packaged and marketed in five discrete commodities: food and wine; grooming; decorating; fashion; and, culture. Marketers took what was stereotypically assumed to represent gay culture and caused it to be reified through its continual repetition on reality television. The influence of the Fab 5 on gay culture has been extensively studied. In 2005 , the influential journal of gay, lesbian and queer studies, $G L Q$ devoted a whole issue to the subject. What is clear is that the influence of commodification on queer culture in general and on the Russell Quant Mystery Series in particular is significant. The stereotypical elements of queer lifestyle that the Fab 5 wrapped up and sold weekly to North American audiences for three years plus re-runs, spin-offs, and pastiche correspond to elements that Bidulka uses to further queer the content of his narratives.

\footnotetext{
${ }^{4}$ See, for example, Michael Bronski's Culture Clash: The Making of Gay Sensibility, as well as Frank Browning's The Culture of Desire and A Queer Geography: Journeys Toward a Sexual Self.
} 
In "Contesting Masculinity's Makeover," Jay Clarkson explores how "Queer Eye's consumer masculinity and traditional masculinity represent highly contested discourses among some straight-acting gay men who resist any changes in the contemporary gender order" (236). Clarkson bases his research framework on recent studies of hegemonic masculinity that explore culturally idealized forms of masculinity in the West today and how they continue to influence the marginalization of women and racialized individuals. M.S. Kimmel, for example, argues that masculinity is the product of historical shifts in how men demonstrate their sense of masculinity. Moreover, in her work, Susan Alexander further demonstrates that masculinity is today not defined by what a man produces but instead by what he consumes (239). Therefore, contemporary cultural research into the shifts in hegemonic masculinity further supports the thesis that hard-boiled fiction is a site where traditional masculinity and the threat of feminized consumerism are explored and managed.

Clarkson analyzes how members of the Straightacting.com website interacted with and contested the consumer masculinity promoted by Queer Eye and explores the meanings of their heteronormative, femiphobic, and homophobic sentiments. In Queer Eye, manhood is equated with vanity, consumption, labour, and a fluency in a variety of class-inflected taste categories (239). Bidulka's work constitutes a similar site of struggle between differing discourses of masculinity: "this idealized manhood is centered on the consumption of beauty and hygiene products and services, extravagant foods, high-end couture, expensive furniture and involvement in high culture" (239). Clarkson's thesis is that gay men's struggle over competing forms of masculinity can be seen in the contest between the conditions of corporate capitalism that seek to transform masculinity into a 
consumer model and gay men who seek to preserve the hegemonic masculine model. He demonstrates that the website Straightacting.com is one site where that battle is clearly manifested. Thus, one can read Bidulka's work as a similar site of struggle between hegemonic masculinity and gay consumer masculinity. Russell Quant has a foot in each world, presenting himself as a straight-acting gay man embracing traditional masculine values yet he is drawn to consumer masculinity and validated by the types of consumer choices he makes.

As a consequence, there are some differences between the way Russell Quant presents himself and the ways in which he behaves. A former Saskatoon police officer, he has been inculcated into the "discourse of the law," however, like the hard-boiled private dick there is a strong sense of the loner in Quant. He is not an outlaw now, although given that legislation in Canada has only recently been enacted to protect the human rights of gay and lesbian people, only a few decades earlier, Quant's homosexuality would have positioned him at odds with the law he would have been obligated to uphold. It may be this marginal position that gives him a different perspective from his colleagues in law enforcement: “I liked the work but I just wasn't cut out to wear a uniform and drive a car with a bubble" (Amuse Bouche 33). The law is too repressive for Quant, and thanks to an inheritance from his Uncle Lawrence, Quant is able to start out on his own as a private eye. In terms of appearance, straight-acting gay forms of masculinity are the dominant forms represented and valorized in the series and it is this type of masculinity that Russell Quant himself physically embodies. At the beginning of the series, Quant, 32, describes what he sees when he looks in the mirror:

Not too shabby. I'm six feet tall plus a bit, with green eyes, finger-combed sandy hair and a toothy smile. Based on how often I have to go to the gym, my body is 
certainly not a gift of nature, but rather something I have to sweat over to keep it looking okay. (Amuse Bouche 52)

This is the same self-image that Quant sees later in the series too, and one that is confirmed by his friend Anthony in Stain of the Berry: "You're a six-foot-one, freshfaced, sandy-haired Adonis" (21). It is important to Russell Quant that he be fit and attractive as a single, youngish gay male and equally important to Bidulka's reading audience that the hero of his series be a man whom a gay audience would identify with or desire. While Quant does not display the impenetrably tough-shelled character of the original hard-boiled private eye, physical strength and enough toughness to take regular beatings are very important attributes for him and he regularly works out at a gym to maintain his physique. Certainly, the type of job Quant undertakes as a private eye requires strength and agility: he is physically challenged, attacked and assaulted throughout the series and he is able to withstand this. And yet, as Kittredge and Krauzer observed in The Great American Detective, "the hard-boiled dick is a romantic: he must be, because his grandly optimistic delusion that he, working alone, can maintain society's order, is continually being kicked in the teeth" (xvii). Quant is a hopeful romantic, too, in that he equates leaving the Saskatoon city police force and becoming a private eye with "buy[ing] a dream" (Amuse Bouche 33). He is also a romantic in his everyday life: Bidulka devotes many passages in the novels to Quant's flirtations with most of the men he encounters during his investigations. As the series progresses, Quant finally becomes enamoured with his uncle's security guard, Alex Canyon, with whom he begins a relationship in Stain of the Berry.

Moreover, through Bidulka's use of the first-person narrative, which is a typical format for the private eye novel, the reader comes to understand that there is a soft and 
caring quality to Quant that lies beneath his flirting. Quant truly believes in his causes. Moreover, he displays a talent that completely subverts the 'prophylactic toughness' common in even gay detectives such as Dave Brandstetter: Quant can empathize with the criminal. Indeed, he comprehends that the complexities of society and its responsibilities for criminalizing the "other" make for a lot of grey areas where criminals and victims are concerned.

Yet while Quant considers himself to be a masculine, straight-acting gay male, he is very attracted by the materialistic qualities associated with consumer masculinity. Consumption is of such significance to Russell Quant, and ultimately to Bidulka himself, that the title of each of the novels has been conceived and styled around a narrative element dealing with food and drink, from the amuse bouche appetizers Quant tastes in France to the sundowner drinks he enjoys on safari in Africa. Clarkson argues that in Queer Eye occupational achievement, one of the constitutive elements of masculinity "is not eliminated but is signified through the conspicuous performance of a high level of taste literacy" (240). Bidulka is signaling through cultural codification in the title of each novel, a certain sophistication and competency in food and drink, as well as a hint of the exotic. This coding suggests to the gay reader who shares these values that they will identify with Russell Quant and the narrative's constitutive signs of gay consumer masculinity.

The role of food is minor to non-existent in hard-boiled stories: eating is what one does to survive. In Bidulka's work, fine dining goes hand in hand with Quant's investigational travels; the series is peppered with longish descriptions of the meals he 
consumes and his knowledge of local cuisine. The following two examples are characteristic:

We began with fresh Arctic char sushi, followed by a creamy French Canadian pea soup served with fresh-baked breads, then grilled musk ox accompanied by fantastically flavoured, oven-roasted vegetables mixed with semi-sweet local berries. Each course was paired with magnificent wine. (Stain of the Berry 192)

The buffet was a veritable free-for-all of African delights: bobotie (ground lamb topped with egg custard with yellow rice), mealie bread, samp (a boiled corn dish with sugar beans), chakalaka (a sweet and spicy blend of cabbage and beans), snoek fish, and plenty of amagwinya (tiny balls of chewy fried bread). (Sundowner Ubuntu 137)

Clearly, these descriptions, emphasizing the sumptuousness of the meals and their exotic nature, would not be out of place among the pages of Martha Stewart Living. Such descriptive passages further enhance the characterizations encoded in the titles of the novels and Quant's masculinity is here represented as consumer masculinity through an affinity with taste and affluence. His occupation and his upper-class contacts enable him to travel and enjoy food leisurely as entertainment.

Contrary to food, alcohol has played a very noticeable role in hard-boiled detective fiction, as well as in crime writing that developed in the latter half of the twentieth century. Since the late nineteenth century and most certainly from the time of Prohibition (1920-1933) to the present day, the consumption of alcohol has been and continues to be a moral issue in North America. The practice of men drinking in the hardboiled subgenre is seen to represent an experience of men's camaraderie, as helping to create a male space for entertainment and for male homosocial bonding. Smith suggests that excessive drinking in some early hard-boiled stories, such as those published in Black Mask, represent men's challenge to prohibitionist's authoritarian control over men's bodies and hence a rebellion against the threatening femininity since the 
temperance movement was dominated by women (98). Indeed, the contemporary imperative for morally responsible drinking, while certainly not restricted to either gender, does still tend to be culturally associated with the feminine as the organization name Mothers Against Drunk Driving suggests.

Bidulka's relationship to drinking is far less dark and extreme than that explored by Chandler in The Long Goodbye, for example, but in each of his investigations, Russell Quant turns to alcohol. In his case, however, his use of alcohol, mostly expensive wine and fancy cocktails, is more for pleasure and entertainment than that of his predecessors straight or gay. Philip Marlowe, Raymond Chandler's drunks, and Benjamin Justice all use alcohol as a coping mechanism to deal with the unstable economies and corrupt institutions that they find themselves faced with, as a crutch to help them stand up to threats to their masculinity. This can be seen to be the case in Wilson's Benjamin Justice series, which features Justice as a fall-down-drunk investigative journalist who abuses alcohol to kill the pain of his unfortunate circumstances. Michael Nava's private investigator, Henry Rios, on the other hand is a recovering alcoholic who attends meetings at Alcoholics Anonymous. Nava is perhaps offering a positive image to gay readers that dependencies can be overcome. But the question here remains whether or not it is a realistic portrayal or rather more simply hopeful and romantic. Quant's use of drink does not appear to serve this purpose. Bidulka's hero tends to drink at parties with his friends and during his travels abroad but usually not to excess. His descriptions of the alcoholic beverages that he consumes suggests that he sees himself as a connoisseur. During his trip to South Africa, for example, Quant appears particularly proud of his newly-gained knowledge of local wines: "Along with the food came my first ever bottle 
of Pinotage, a superb, gently oaked Beyerskloof from the Stellenbosch wine region just outside of Cape Town" (Sundowner Ubuntu 122-123). This signals another form of a Queer Eye occupational achievement.

The significance of capitalist consumer economy to hard-boiled fiction has been further argued by Smith in her reading of class through the clothing styles afforded the private eye. Smith examines the opening passage in Raymond Chandler's The Big Sleep (1939) where Philip Marlowe describes in detail his appearance as he makes his way to the first meeting with his new client, a California millionaire. Smith reads Marlowe's dressing for success coupled with his 'flippancy about self-presentation' as functioning didactically for working class readers. For her, "Marlowe and his colleagues taught not only 'legitimate' modes of self-presentation, but also the legitimate way of deploying such knowledge-casually, with an air of entitlement, of "bluff"' (Smith 107). The ways in which the hard-boiled private eye manipulated consumer items, in this case bourgeois attire, worked to help working-class readers to navigate the stresses of the new capitalist consumer marketplace.

Clothing is a similarly significant issue in Bidulka's work, and he uses it to raise issues of gender and class. Russell Quant's clothing choices in particular, rather than functioning pedagogically for readers, arguably signify once again the establishment of gay consumer masculinity. The series is rife with Quant's comments regarding what everyone is wearing; these comments are most ironic as regards Quant's attire. Although he cites as one of the reasons he left the Saskatoon police force that he "just wasn't cut out to wear a uniform," Quant's favourite article of fashion is his one pair of "wonderpants": "They are black, never wrinkle, and I've owned them forever yet they're 
always in style and, most importantly, I've been told that they make my ass look great" (Amuse Bouche 51). In fact, Quant is so partial to his wonderpants that he wears them continually and they keep turning up in his closet and in his luggage throughout the series: "I could always count on my wonderpants" (Amuse Bouche 120). Ironically, Quant has a habit of pairing his wonderpants with a light shirt and a dark jacket which in effect becomes his private-eye uniform. In Detective Agency, Walton and Jones point out an interesting issue regarding fashion in Sue Grafton's Kinsey Malhone novels:

Kinsey, who wears jeans and turtleneck sweaters, has an 'all purpose black dress,' adaptable to any situation requiring more conventionally feminine attire: 'black with long sleeves, in some exotic blend of polyester you could bury for a year without generating a crease.' (101)

Given that Quant's black wonderpants "never wrinkle," even after being buried at the bottom of his suitcase, one has to assume that the intertext is more than coincidental here. Using fashion to disrupt normative masculinity, Bidulka has created a gay "little black dress" for Quant. Like Malhone's dress, Quant's wonderpants become a "running joke” as fashion retailer Anthony Gatt is forever trying to get Quant out of his wonderpants and into something befitting a gay man of style. Moreover, Quant's repeated reluctance to accept Anthony's continual gifts of fashionable clothes suggests a desire to remain in uniform, in the straight-acting camp of masculine gay men perhaps. Ultimately, in each case, however, Quant accepts Anthony's presents and then wears them, if not always comfortably. His acquiescence suggests that the marketing model of mass gay consumer masculinity is increasingly becoming the new "uniform" of consumer masculinity. At the same time, Quant can work and lounge in his more conventional clothes but with the aid of Anthony he can get all dressed up as Queer Eye would instruct for special occasions. This effectively permits him to keep one foot in each "camp" so to speak. It also reveals a 
double role for Anthony. He is a Queer Eye fashion guru/make-over artist for Quant. Yet by supplying Quant with clothing and taking him out for dinner and drinks, Anthony also plays the role of sugar daddy. Bidulka is clearly playing with gay stereotypes here.

Travel and mobility is another aspect of Queer Eye consumer masculinity and is also a factor that has traditionally distinguished the private eye from the amateur detective. The detective is basically static: remains in one place to interview suspects. A contemporary example of this traditional approach can be found in Jackie Manthorne's Final Take, in which lesbian physical education teacher Harriet Hubley finds herself searching for clues following the murder of a former classmate during her high school reunion in Halifax. While the novel involves travel in that Harriet flies to the reunion in Halifax from her home in Montreal at the beginning of the novel and returns home at the end of her investigation, the majority of the narrative takes place at the lake house where the inevitable murder occurs.

Whereas the whodunit of the Agatha Christie type tends to take place in a rural or other non-urban setting, such as the seaside, the hard-boiled detective novel has historically been set in large urban centres, in the depths of the city complete with its grime and crime. Furthermore, given its more isolated setting, the whodunit tends to offer a limited number of characters and suspects, all of whom the author usually introduces at the beginning of the narrative. It also follows that there is little movement in the ratiocinative detective novel, as all of the information relative to the case at hand is accessible in one place, whereas the hard-boiled private eye tends to be very mobile, his agency involving much action, movement and often travel throughout the urban centre and beyond. The private eye can encounter an ever-growing number of characters and 
suspects, and the plot can become more and more complex as the detective moves from place to place and person to person in his or her investigation.

The private eye, on the other hand, is noted for his or her mobility. Originally, this was a case of moving from place to place to interview characters. In the Russell Quant Mystery Series, Bidulka takes the private eye's agency to new extremes that readers of the more traditional genre would not expect. Indeed, agency is a pivotal word here as the number of times Quant requires assistance from a travel agency is exceptional in private eye standards. In his five investigations, Quant manages to visit France, New York, the Mediterranean (including Tunisia and Italy), Vancouver and the Canadian Arctic, as well as South Africa and Botswana. Indeed, it is important to note that whereas sleuths like Agatha Chistie's Hercule Poirot and Manthorne's Harriet Hubley tend to stumble upon a crime while on some form or personal or business travel, Quant does not travel of his own accord. Quant is first hired by his clients and is subsequently sent packing in order to investigate the crime. Harold Chavell, Daniel Guest, Charity Wiser, the Culinaire family, and Mrs. Ridge all prepay Quant's travel to the local and exotic destinations he visits. While all of Quant's travels are clearly tied to his investigations, Bidulka seems to spend an inordinate amount of time informing the reader of his travel so much so that in certain instances his novels begin to read like a gay travelogue:

There are over four hundred Relais \& Chateaux properties situated in about forty countries. My next destination was one of this elite chain of mostly privatelyowned and operated hotels. Each property is unique but promises the outstanding quality necessary to be included on the peerless list of Relais \& Chateau establishments. Guests are guaranteed a certain standard of accommodation and cuisine, oftentimes the finest the host country has to offer. (Amuse Bouche 49)

My bright room - a junior suite no less ( I love Roy) — was actually two separate rooms - a sitting area and a bedroom - connected by two doors thrown open between them, plus a lovely bathroom. Multiple windows revealed a most 
astonishing view of the buys V\&A Waterfront and Table Mountain beyond it. I took a seat at a small writing table in front of the floor-to-ceiling windows and pulled out the Visitor Guide map the front desk clerk had handed me. (Sundowner Ubuntu 116)

Again, this is part of the Queer Eye occupational expertise that Clarkson argues underpins gay consumer masculinity. The link between travel, comfort and consumption are obvious in these examples. Clearly, the author has relied upon the "write what you know' credo because prior to his writing each of the novels, Bidulka himself had travelled to most of the locations he describes. Beyond the blurring of fiction and reality in these instances, there is also a distinct entertainment value to the travel accounts. As a private investigator from Saskatoon, Quant cannot afford to visit these places on his own dime and although he travels for business, he is clearly presented as a tourist in each locale enjoying himself as much as possible: there is always time for wine, good food and some eye candy. There is often a much more relaxed and luxurious feel to these novels than would be afforded by a more issue-driven private-eye novel. The locales offer less grit and more glamour. One can presume this to be another form of queering the genre: the demographic that forms Bidulka's principal audience is part of a cultural group that places great value on mobility and travel. Moreover, it may also have much to do with the author's own experience of his place in Canada for he describes being from Saskatoon as "being from a city where (sic) almost everybody leaves" (Ruttan 64).

While the Russell Quant Mystery Series takes Saskatoon, Saskatchewan as its home base, unlike the many private-eye series that have gone before it, this series does not comprise a set of investigations that play out primarily in one urban centre. While the novels adhere to the formula through the use of urban settings, and while most of the 
narratives begin and end in Saskatoon, often in Quant's home, the majority of the action in most of the novels takes place beyond the Saskatoon city limits. The settings for the novels are, however, by no means rural. Rather, they are marginally urban, that is not centralized in the mean streets of the concrete jungle but liminal to them. Indeed, Bidulka's settings are almost always off-centre— just outside of downtown. There is a constant tension between the rural and the urban, as, perhaps, in Saskatoon, the never ending prairie is never that far away from the city centre. When Quant steps onto the small deck outside his office, for example, he "can look across Spadina Crescent into beautiful Kiwanis Park and the swiftly flowing South Saskatchewan River" and the prairie that lies beyond (Amuse Bouche 9). And, during what appear to be a "cruising" scene at the beginning of Flight of Aquavit, it takes Quant only a few moments to be lured into "leaving the safety of the city" (9). Contrary to the "classic" hard-boiled form, for Quant it is the rural setting that represents danger and the city that offers him security.

Since both figuratively and literally the rural is central to the urban in Bidulka's Saskatoon, I would hold that the tensions created through the various backdrops for Bidulka's narratives reflect a combination of his Canadian and gay experience. For as Bidulka describes it, even at home, Quant is neither in the city nor in the country: "The house is on a large lot at the dead end of a quiet, little-travelled street. A grove of towering aspen and thick spruce neatly hide it from view of the casual passer-by. Even some of my neighbours don't know the house is there" (Amuse Bouche 32). With an enchanting mix of flora and fauna, Quant's home first reminded him of a fairy tale forest with elves and fairies, which he says humorously made him feel right at home. Clearly, this is a rather feminine landscape for the private eye, if not just a bit queer. 
A survey of but a few of the locations Bidulka uses in Amuse Bouche and throughout the subsequent novels further reveals this ambivalence about location and the accompanying tension between traditionally masculine and feminine aspects. Quant's office is located in the PWC Building. The name PWC stands for the former Professional Womyn's Centre and now that Quant's friend's partner Errall Strane has purchased the building, she has accepted him as a business tenant. This makes Quant the only male to penetrate the female office space in over two decades. On the one hand it can be read as an ironic comment given that at the outset of hard-boiled detective fiction, a significant factor in the perceived threats to working-class men was the influx of women into the workforce. At the same time, this could be a comment on Quant's gay consumer masculinity. After all, he is not 'macho,' so is he just one of the girls?

The home of Howard Chavell, Quant's first big client, is located in Cathedral Bluffs, "about a dozen kilometers northeast of the city and features five-to-ten-acre parcels of land off either side of a gravel road. [The house took] full viewing advantage of the South Saskatchewan River valley over which it was dramatically perched." (10) As rural as it might appear from the outside, inside it is a "five-star luxury hotel" (11). Indeed, location is never really what it appears to be. In his initial search for Tom Osborn, Chavell's fiancé, Quant investigates Osborn's apartment in central Saskatoon: the tiny apartment reveals itself to be mostly empty of life. It is really just for show, for both Chavell and Osborn spend most of their time together at Chavell's cottage on Pike Lake. This idyll turns out to be the location of Tom Osborn's murder.

The succeeding novels also all present liminal locations as settings for Quant's investigations, for subsequent criminal acts and for Quant's confrontation with suspects 
and killers alike. Flight of Aquavit begins with a car chase beyond the city limits of Saskatoon, at night, in the dead of winter. The final confrontation with the murderer in Tapas on the Ramblas occurs in a summer villa in the Italian countryside in Tuscany. In Stain of the Berry, Jared Lowe's Jeep Cherokee is attacked by the Boogeyman in a Saskatoon berry field; in the final confrontation, Jin/the Boogeyman attempts to rape Quant in a trailer park located on the wrong side of the tracks in west Saskatoon. Sundowner Ubuntu finds the hero and Cassandra Wellness in the thrillingly absurd situation of being chased by a band of thugs in the liminal no-man's land of the border between South Africa and Botswana. As Quant moves from location to location, the paradoxes and tensions between urban and rural and his constant decentralization represent a coherent threat to his masculinity which is repeatedly questioned throughout his investigations.

Moreover, it is perhaps not accidental that whereas in the traditional hard-boiled detective story the major threats come from organized crime, corrupt police and the sexually questionable femme fatale, the majority of attacks on Quant and other characters take place in an outdoor environment involving some aspect of nature. The relationship in Bidulka's work between the masculine and the feminine is further underscored by the tenuous relationship he has with nature. In some cases, this results in a battle of survival against the elements.

One of the most startling and significant incidents where Quant fights for survival in spite of the elements occurs in Flight of Aquavit, where Cheryl Guest schemes with her brother to have Quant punished when she mistakenly believes that Quant is having a secret sexual relationship with her husband Daniel. As Quant is lured into a van to help a 
neighbour move a desk, his best friend Jared unexpectedly turns up to help; when the truck doors slam shut they both find themselves prisoners. This is a striking metaphor for the heteronormative control of the homosexual through quarantine, exile, and ultimately murder. Both Quant and Jared, best friends representing both active and passive ideals of the gay community, find themselves dumped in the vast, empty prairie at night during a raging blizzard. They have literally been moved from centre to periphery, banished by Cheryl Guest and her brother, who stands in for Cheryl's unfaithful husband, representative of the dominance of the lawful heterosexual family over the illicit homosexual relationship. So engrossing is this image and storyline that Bidulka seems to forget all about the investigation that forms the basis for the novel. The narrative here now focuses entirely on Quant and Jared's life-and-death struggle on the Canadian prairie during a winter storm. But survival in this instance does not come as a result of great heroism or uncanny know-how (survival tips). Rather, it comes in the form of an abandoned barn and farmhouse, remnants of the civilization from which they have been driven. Of course, the farmhouse comes complete with "half a 1.75 litre bottle of Canadian Club rye whisky" that they "cut with snow melted over the fire" (382) and a smorgasbord of tinned meats, vegetables, and fruit. They do not actually conquer the elements but rather, they survive by waiting for the storm to pass. Yet once the storm has abated, Quant and Jared are still lost and unable to get themselves to the safety of home.

The resolution of this survival scene, and therefore the restoration of order, is achieved when police detective Darren Kirsch arrives on the scene to find the two lost men and take them home. In this rather queer situation, the law which until only a few decades earlier was used to quarantine and repress gay people, now comes to their rescue. 
Saskatoon city police detective Kirsch does not come alone, but rather "with two RCMP officers at his heels" (387). In this instance, then, it is the social ill of homophobia as executed by Guest and her brother, not homosexuality that is condemned by the law. One cannot, however, fail to recognize the ambivalence of the scene as concerns the central theme of masculinity. Indeed, these are three presumably heterosexual police officers, who rescue two gay men in the wilderness. Their penetration into the winter wilderness brings upon the virginal snow-covered prairie a colonizing and civilizing effect which is further underscored by the feminization of Quant and Jared, who "cuddled up on the couch in front of a roaring fire, full of corn and tuna and a little slap-happy from downing rye shooters" are reduced to the roles of consumers in their use of a blanket, canned goods and a cozy fire in a fireplace to survive (387). That Kirsch and the RCMP are drawn to the "little house on the prairie" because of smoke from the chimney can conjure stereotypical images of native smoke signals that call out the presence of the Aboriginal "other" in the wilderness to the civilizing order of the Mounties. Yet this complex image that invokes the colonization of the "other" is whitened and strangely complicated by the conclusion to the episode wherein "one of the RCMP officers put[s] out the fire" and Quant and his friend Jared are returned home to the symbolic order by the conventionally masculine and heterosexual Kirsch flanked by members of Canada's "national" police.

Quant is secretly sexually attracted his friend Jared. Since Jared is in a relationship with Anthony, Quant is morally bound not to act on his feelings. During their ordeal in the prairie blizzard, Quant respects the boundaries of their relationship although he has the opportunity to transgress them. Their safe return home by forces that represent 
heteronormative discourses of the law is perhaps symbolic of the affirmation of this boundary between the two men.

Jared and his partner Anthony possess similar though less hegemonically masculine attributes in comparison with Quant. Anthony is described as "a man of indeterminate age and means...with a dashing Robert Redford/Great Gatsby handsomeness to him. He knows every word created by man and then some and speaks them with a smooth English-accented flourish" (Flight of Aquavit 94). Accordingly, he could be said to represent the by-gone genteel and more feminine form of Victorian masculinity but his would only hold true for his appearance and manner. Anthony is the owner of "a high-end menswear store" called gatt "from where, for a price, even the most slovenly can emerge a gentleman of breeding and exquisite taste" (94). With this kind of an introduction, he would fit right in with the Fab 5 and represents the sales end of consumer masculinity; he is continually trying to dress Quant in the latest fashion. Anthony's partner, Jared Lowe is a jet-setting model. He has "impeccable olive skin," "boyishly unkempt curls," and "golden-green eyes" (211). As a model, Jared represents the marketing aspect of consumer masculinity. Indeed, Quant is surrounded. He finds Jared irresistibly beautiful and admits to himself on more than one occasion that he would be in love with him if Jared were not Anthony's partner.

But Jared is not the only other man whom Quant finds attractive and with whom he engages in continual flirty behaviour. Darren Kirsch is a Saskatoon city police officer and former colleague of Quant's who somewhat begrudgingly helps Quant out with information relative to his investigations with the understanding that Quant will do the same for him. Kirsch is "six foot plus, with a top heavy, muscular body, short, dark hair, 
neat, dark moustache, deep-set stern eyes" (Amuse Bouche 151). Despite his being "the archetype (sic) City of Saskatoon policeman" and "as het as a muscle car" (151), Kirsch is endowed with a subtle softness that underscores his dedication to the truth. His character is nonetheless very much a stereotype and serves to differentiate Quant from the formulaic cop.

Besides containing stereotypes, like much popular fiction, Bidulka's writing is also similar to detective series that have preceded his novels in that they appear bound very closely to the circumstances in which they are written and read. Moreover, like much popular fiction, the Russell Quant Mystery Series appears to reflect the tastes and the limits of what has been acceptable in Canada at the time that it is produced. This can be expected in genre fiction, for as Walton and Jones note, "trends in popular fiction, especially realist fiction, are driven by changes in society and in what readers are willing to 'buy' in both the literal and metaphoric sense of that word" (12). What Bidulka's readers seem to be willing to buy, given his popularity in reading circles in mainstream gay communities, are the same types of themes popular in mainstream gay culture today.

Certainly, as far as the overarching themes of his novels are concerned, it would seem that Bidulka has taken his cue from the front pages of popular gay and lesbian newspapers and magazines. It is probably no coincidence that his first novel, Amuse Bouche, which was published in Canada in the fall of 2003, begins with an investigation that is set off by a gay marriage gone wrong. Since the late 1990s, same-sex marriage had become a top-of-mind topic within the mainstream gay community in Canada. By June 2003, when it was legalized through the courts in Ontario, same-sex marriage was a hot topic in the mainstream media across the country. By the time Amuse Bouche was 
released in the United States in 2004, gay marriage had also been legalized in Saskatchewan, where the fictional wedding between Harold Chavel and Tom Osborn was to have taken place. Finally, once Insomniac Press re-released Amuse Bouche in mass market paperback format in Canada, same-sex marriage had become the law of Canada with its official proclamation by the Government of Canada on July 19, 2005.

In Canada the topic resonates within the bounds of what is legally acceptable. This is important because a significant cultural function of realistic genre fiction novels can be found in their treatment of the topical which readers can use as a means to negotiate expanding notions of accepted reality and alternative versions of it. As Walton again notes, "in one sense, realist fiction defines and conventionalizes the limits of its audience's shifting conceptions of reality at the same time that it allows its readers to explore, mediate, and manage their fantasies and fears about those limits" (3). There is no evidence to suggest that people who find same-sex marriage morally reprehensible, however, would read this book. Nonetheless, this idea helps to explain how this novel could continue to be relevant and accessible in the United States, where currently gay and lesbian marriages are recognized in only two of fifty states, while elsewhere public debates about same-sex marriage rage on, especially in this American election year. Bidulka's second novel, Flight of Aquavit, presents Quant investigating the blackmail of a man married to a woman while he undertakes secret sexual liaisons with men. First published in Canada by Insomniac Press in 2004, Flight of Aquavit comes at a time when issues of bisexuality and the "down-low," a term used to designate issues of African-American men engaging in secret homosexual activities while living publicly heterosexual lives, went from being issues circumscribed by the gay and African- 
American communities, to become issues for mainstream media in both the United States and Canada. The New York Times, for example, published a cover story on the down-low in August 2003, while Oprah Winfrey interviewed J. L. King, author of On the DownLow on her syndicated talk show in April 2004. Also released in the United States in 2004, Flight of Aquavit subsequently won the prestigious Lambda Literary Award for Gay Men's Mystery that year. Certainly, issues of heterosexual marital infidelity involving one partner's secret homosexual affairs are not issues restricted to the AfricanAmerican community, nor are they new. But the down-low came to light at a time of renewed interest in issues of racism and gay rights in the United States. The currency of the issue was also felt in Canada, as here issues of "outing" have been in the public eye since the mid-1990s.

Perhaps the least noticeably topical of the five novels is Tapas on the Ramblas, which, published in 2005 , might also be the author's least literarily successful. The novel features Charity Wiser and her lesbian partner Dottie Blocka leading the members of the Wiser clan on a Mediterranean cruise while Russell Quant seeks to uncover the identity of the mysterious family member who has poisoned the elderly matriarch's dog and made death threats against her. Issues of criminality aside for the moment, the novel does raise the theme of homophobia, particularly within one's own family. Here, however, a significant twist in novel's plot is that Charity Wiser has embarked her whole family on a gay cruise, so that as the minority, the homophobic relatives do not have an overwhelmingly heteronormative environment to support them in their hostility towards Charity Wiser and Dottie. Accordingly, they must struggle with being the sexual minority in an inverted society on a boat aptly named the Dorothy II. Thematically, one 
can say that this book is the least significant and least relevant to the gay community in Canada and especially to its readers. All evidence points to Bidulka's audience being made up chiefly of gay men and older straight women. The book does begin to look at issues of homophobia in a general way which is a lead-up to the more focused approach Bidulka takes in regard to this theme in the two subsequent books.

Stain of the Berry, published in 2005, presents most clearly the themes of internalized homophobia and racism within the gay community itself and their criminalizing consequences. These are issues that have been important to the community since public organizing began in the late 1960 s, yet they are more particularly relevant in Canada today. Specifically since the adoption of federal legislation allowing same-sex marriage in Canada, many members of the mainstream gay community have voiced concerns over the direction of gay and lesbian and queer activism. While gay and lesbian communities are necessarily as diverse as the Canadian population, they do not necessarily reflect this diversity visibly and in their battles for social justice.

Bidulka's most recent novel is Sundowner Ubuntu. It also features a very focused theme of homophobia, although in this novel, published in the fall of 2007 , the story concentrates on how an incident of homophobic bullying at school has led to unexpected consequences of danger and violence that envelop many more lives than the few involved in the original incident. Homophobic school bullying has become a priority social issue in the Canadian media over the last couple of years; with the fight for same-sex marriage rights having been won three years ago, mainstream gay activists have been focusing on visible and violent acts of homophobia and several campaigns have been launched in 
school boards in a bid to educate children, youth and parents about issues of homophobia in schools.

Even before exploring the issues of criminality that Bidulka deals with in the series, one can see clearly an overall set of themes, from same-sex marriage, to outing, to homophobia and homophobic violence that resonate with the gay and lesbian community and will continue to do so well into the future. What these themes also have in common is that in today's culture they are fundamentally about rights: the right to marry, the right to love whomever one wants and the right to live free of hate and violence. Through the themes presented and the exposure of criminality Bidulka is signaling that all is not as rosy pink in contemporary Canadian society as the gay mainstream might like its constituents to believe. Many gay community leaders, activists, and commentators have questioned where to focus efforts for change today. So much queer activism was targeted to same-sex marriage, that with its realization in 2003 the drive for equality and the expansion of rights has become diffuse, with many gay people questioning why one should keep fighting "when we have all our rights now." Of course, this is very insular thinking and Bidulka deftly points out that heteronormative social systems continue to marginalize and oppress individuals and groups through continuing homophobia and other forms of hate and denial of human rights. Like much feminist and lesbian detective fiction that preceded it, Bidulka's work indicts society as the responsible party for the criminal impetus and the individual and collective ills that result from the commission of these crimes. Accordingly, while detective fiction has been theorized as normative and to a great extent repressive, Bidulka and other gay crime writers also use the form in counter-discursive ways to transform the discourse of rights and the discourse of the law. 
By raising minoritarian concerns such as these, Bidulka and his contemporaries help to extend the boundaries of the genre while normalizing minority rights through an extension of the discourse of the law.

As I demonstrate in the next chapter, Bidulka is by no means a feminist crime writer. His work does, however, add to and become part of the overall hard-boiled detective subgenre and, as such, it borrows from and plays off formulas and concepts that have gone before. One area where Bidulka's work aligns with earlier feminist crime writing is in its association of criminality with society as a whole. As Munt observes in Murder by the Book, "traditional crime fiction exonerates society [and] blames individuals [whereas] feminist crime fiction makes guilt collective and social" (198). Much feminist crime writing posits masculinity and patriarchal systems as the social evil that exploits and victimizes women. This, of course, subverts earlier detective fiction where the hero battled corrupt individuals, succumbed to the sexual trickery of devious women, and eventually triumphed by restoring some form of order that upheld the values of the past that modernity put under threat.

Like many other gay detective novels that have preceded the Russell Quant Mystery Series, these novels explore collective guilt and heteronormative power relations as the causes of individual criminality. Society is the collective cause of the ills committed by the individual. This similarity between gay detective fiction and feminist crime writing clearly has to do with relatable experiences of oppression and marginalization, and in the case of lesbian detective fiction, of homophobia. As regards criminality, the similarity between Bidulka's texts and feminist work ends with the social cause and not with the resolution of the crimes. While much of women's detective fiction 
sees the installation of a social feminist ideology, the endings of Bidulka's novels return to a championing of the individual and the reinstatement of an affluent gay boys' club. To wit in the case of Stain of the Berry, although there is a coming together of the workingclass men and women of Hagar's Heath to save Quant from a brutal assault, the same society that Bidulka blames for creating a monster is afforded the agency to medicalize and institutionalize a homosexual and racial other.

At the same time, where my reading of Bidulka's work sees him depart from gay authors who have gone before him in the creation of gay private eyes is that in making society responsible for the criminality that afflicts the community, gay members of society are not only its victims, they can be the criminals, too. Just as there is a running social critique evident in the content and structural issues I have discussed, so too is there an increasingly sharp indictment of society's role in the development of criminality from the first through to the most recent novel.

In Amuse Bouche, the principal evil is greed, but it is propelled by capitalism and consumerism, the increasing need for individuals to accumulate material wealth. But even deeper than this, the novel shows how homophobia is produced by fear of emasculation that follows from a perceived threat of femininity. For Randy Wurz, representative of the patriarchal affluent capitalist male, gayness is equated with femininity, creativity and servility. In his business partnership with the gay Tom Osborn, therefore, heterosexual, masculine, family man, Randy is the salesman: he has the active role in the partnership whereas Tom is the creator and incubator of ideas, bringing them slowly to fruition, too slowly for his partner. This notion is clearly demonstrated through Randy's declaration to Quant during the investigation into Tom's disappearance: "Like I 
said, Tom spends a lot of time on R\&D. I handle the real stuff—making sales, overseeing production, making sure sales orders are filled. I run the business.” (139)

Eventually confronted as Tom's murderer, Randy explains his motivation, further rationalizing his indictment of Tom's "lifestyle" and its accordant value:

Tom had it so fucking easy! I have a wife and kids and mortgage and car... He had Chavell and their fucking frivolous lifestyle of the rich and famous... Tom could afford to turn it down-I couldn't. (255)

Here, Randy's speech ostensibly indicts capitalistic greed as he assumes the patriarchal and romantic notions of head of the family and breadwinner. This sets up a binarism that further feminizes Tom Osborn and invalidates his partnership with Harold Chavell. Tom's luxuriously easy life becomes a threat to Randy's manhood, so Tom must be eliminated. Granted, Bidulka is limited by the formulaic nature of genre in that he cannot convey such a stark social message without foreclosing social change at least in the short term. Bidulka blames the criminality of the individual on social systems that oppress; in this case, Tom's murder is in part sanctioned by heteronormativity and his death, obviously, means that the novel cannot close with a same-sex union that would symbolize a resolution of greater social impact than simply bringing the criminal to justice.

In Flight of Aquavit and Tapas on the Ramblas, the causes of criminality are similarly tied to greed and materialism. Both mayoral candidate Herb Dufour and travel agent Richard Gray commit murder following a complex web of intrigue and deceit that stem from the desire to advance their social standing, careers, and wealth. In these novels, however, both Dufour and Gray are homosexual and their victims stand in their way of achieving their objectives. Here, feminine intruders, an effeminate gay lover and a drag queen, are identified and destroyed. 
Stain of the Berry and Sundowner Ubuntu work much more obviously at illustrating the damage that can be done to the gay community and to society as a whole by homophobia. Bidulka achieves this effect by very clearly linking homophobia to criminality. In both of these two novels, Bidulka blames society's continued homophobia for creating monsters that take out their revenge on the individuals/community that spurned them. In Stain of the Berry, while he blames society overall, he clearly lays some blame on gay men themselves for the way they express their internalized homophobia outwardly through the marginalization and oppression of others in the community. In his most recent novel, Bidulka offers as a moral solution to the crippling effects of homophobia through the South African ethic of ubuntu, which he defines as "the deep sense that each of us is an integral part of the thread of humanity and that we must all take care of one another to take care of ourselves" (263). 


\section{Chapter Three:}

\section{Gender/Class/Race and the Making of a Boogeyman}

‘Are you ready? Are you ready for me?' his hateful voice gurgled near my ear.

(Sundowner Ubuntu 277)

As demonstrated in the preceding chapter, Bidulka effects an initial queering of the detective genre, particularly "classic" hard-boiled detective texts, through his representation of gay consumer masculinity in contest with hegemonic masculinity, as well as through a critique of heteronormativity in his representations of criminality. Bidulka's rather robust embrace of a gay consumer masculinity as demonstrated by his insistence on elements of gay consumer style, including the commodities of food and wine, grooming, decorating, fashion, and culture also sets the series apart from the foundational gay detective series developed by Hansen and Stevenson and the gay hardboiled outsider series featuring outsider Benjamin Justice. Bidulka's representations of masculinity and his indictment of heteronormative power structures in contemporary society can be read by his gay audience as counter-discursive. The narratives push the normative boundaries of a form traditionally viewed as repressive to gays and lesbians outwards to create space for marginalized individuals to be incorporated within the discourse of the law.

Yet, this counter-discursive function works almost exclusively for an unmarked community of white, middle-class and affluent gay men. Bidulka's representation of women, both lesbian and straight, as well as his management of issues of race and class 
are in fact normative and in many cases repressive. Therefore, rather than celebrating a queering of the genre and insisting on progressive and anti-discursive elements of Bidulka's work, in this chapter, I explore how the Russell Quant Mystery Series manages and regulates individuals not represented by the dominant gay male voice. I begin with a focus on gender, specifically on Bidulka's portrayal of women and Russell Quant's ambivalent relationship to femininity. The concept of struggle between hegemonic masculinity and gay consumer masculinity continues to underpin my analysis. I then undertake a review of the marked and unmarked class issues in the series, which can be further illuminated by Smith's study of the hard-boiled subgenre and its working-class male readers, as well as Cover's notions regarding queer class. Finally, I examine how Bidulka manages issues of race by undertaking an analysis of his making of the boogeyman in Stain of the Berry. This reading is enhanced by Sedgwick's and Butler's theorizations which trouble issues of gender and performativity, as well as by Kristeva's concept of the "abject."

As I noted in the first chapter, in traditional hard-boiled detective fiction of the pulps and subsequent works by authors such as Hammett, Chandler, and Spillane, women are portrayed generally as falling into two distinct categories. They are sexual predators who are presented in the form of the femme fatale, who is sometimes introduced as a passive victim who becomes deadly, or in the form of the "office wife," a very capable and independent woman to whom the private dick is not attracted. Certainly, women's crime fiction brought many changes to how women were depicted in the genre; in some cases, feminist and lesbian detective fiction of the 1980s and 1990s completely inverted 
the former paradigm, demonstrating men's weaknesses, inability to function without women, and even relegating them to marginal roles in gynocentric narratives.

A function of the detective genre, like all genre fiction, is that authors often draw on the work of previous writers to mimic them, parody them, or transcend them. While Bidulka is interested in representing a "minority" or previously unrepresented viewpoint in detective fiction (in the way that writers of feminist and lesbian detective fiction have been), he presents particularly problematic images of women in his texts. There are ways in which Bidulka's work could be read as anti-feminist. Indeed, some twelve years after Susan Faludi documented the North American backlash against feminism and a rise of destructive stereotyping against working and professional women, Russell Quant may be telling us that in 2003 , this backlash has reached Saskatoon. On only the second page of Amuse Bouche, Bidulka sets the tone for this novel and for the whole series regarding Quant's relationship to women and his (mis)understanding of the women's movement overall. Here Quant tells the reader about the history of the PWC building where his office is located:

Back in the early eighties when it was cool to delete the reference to 'man,' a group of professional women bought the building and rented space to female tenants who ran female-oriented businesses. For several years the Professional Womyn's Centre was a success. But as the nineties matured and women overall became less hung up about the 'man' thing, what was once politically correct became a bit of an embarrassment and serious-minded tenants moved out. (8)

In one short paragraph, Bidulka writes off decades of women's struggle against oppression, reducing one of the most significant social movements the West has known to an early 1980 s debate about political correctness, a game of semantics, and the creation of women-only work spaces. His implication that feminist struggles are immature and 
have been outgrown by serious-minded people is rather shocking considering that as a gay man, he and other queer people owe much of their social acceptance and human rights gains today to the pioneering activism of first-and second-wave feminists working side by side with gay men during and after Stonewall, throughout the 1970s, and during the onset of the AIDS crisis in the 1980s and 1990s. For Quant, and presumably Bidulka, these feminist "beadmakers and crystal readers" are relegated to a "piece of history" that is no longer relevant or understood. Quant concludes: "I believe, if I was to ask the average 'myn' on the street what PWC stands for, they wouldn't know' (8). With this final remark, which intends a humorous play on words between 'womyn' and 'myn,' occurring in only the first few pages to his first novel, Bidulka distances his series from groundbreaking feminist, lesbian and gay socialist crime writing of which his work is inescapably a part. Accordingly, while the theme of feminism is not raised again in the series in such an overt manner, Bidulka has staked out an post-feminist politics that results in an irrational femiphobia and sets up a framework of constant tension between masculine and feminine that I argue plays out in all matters of form and content throughout his series. An exploration of this tension in regards to Bidulka's female characters demonstrates both an updated reproduction of the traditional roles of women in the hard-boiled, including the archetypes of the femme fatale, the passive victim, and the office wife.

As the central narratives of Bidulka's novels concern his work as a private detective, I begin this chapter with an exploration of female characters who work alongside Quant and examine their roles and relationships to him in his home away from home, the office. Throughout the series, the other tenants of the PWC building, while 
ostensibly professional women in their own right, function primarily as support to Quant in his investigations and in his personal life. The four women who work at PWC are Errall Strane, a lawyer, lesbian and partner of Quant's friend Kelly Doell; Beverly Chaney, psychiatrist; Alberta Lougheed, psychic; and, Lilly, receptionist for the PWC professionals. Notably, the names of each of the women corresponds with the degree of heteronormative masculinity or femininity with which Bidulka endows each character, and that aspect corresponds to the type of work they perform. Errall itself is a rare name, most closely related to the masculine name Errol, and coupled with the surname Strane, conjures up the conventionally masculine image of someone of independent thought following his or her own stream in life. Fittingly, Errall performs the most conventionally masculine occupation of the four women; furthermore, she is not part of a law firm, but works for herself and is presented, in spite of her relationship with Kelly, as one of the most independent women in the series. Beverly undertakes a profession that has traditionally been a man's job but has become associated with both men and women. Her name can be applied to men or women and she is described as "a pretty brunette in her mid forties with twenty extra pounds that look just right on her" (Flight of Aquavit 26).

Bidulka applies the name Alberta to the resident psychic, arguably the most conventionally feminine profession of the four, whom Quant sees as eccentric, brightfaced, and "looking a little bit like Jann Arden as a gypsy" (Tapas on the Ramblas 59). Bidulka associates Errall with expensive art, Beverly with colour schemes, Alberta with aural projections, while the feminine and ever-cheerful Lilly plays the receptionist for the group. While Errall, Beverly, and Alberta do not correspond to the classic character of predator or victim, they are each highly stereotyped. Moreover, they play a supporting 
role to Quant in a way similar to what Erin A. Smith has called the "office wife." Referring to Sam Spade's secretary Effie Perine in The Maltese Falcon by way of an example of this portrayal of women in hard-boiled detective fiction, Smith observes:

Simultaneously commercial/public/masculine and domestic/private/feminine, the term showed the way in which secretaries straddled two formerly separate spheres...Even if not sexually involved with her boss, an office wife owed him the other duties of her sex-domesticity, passivity, charm and an endless patience. (155)

Granted, each of the women at PWC is a professional in her own right, though we hardly see them exercise their work behind the closed doors of their offices. Rather, as Quant does not have a detective's assistant or sidekick associated with his job, each of the women takes on aspects of the role of the office wife. They have coffee made; sometimes they feed him. Errall provides legal and rational advice and assists Quant with legwork for some of his cases. Beverly is somewhat of a motherly figure to Quant but is also instrumental in providing information that leads to Quant's discovery of the blackmailer and the murderer in Flight of Aquavit. Alberta, while being portrayed as a new-age flake, helps Quant to narrow down suspects aboard the cruise ship Friends of Dorothy due to her aural projections which point Quant to a would-be killer. Furthermore, an obvious queering of the role of "office wife" is evidenced by Errall travelling on the Mediterranean cruise with Quant, all the while serving as his beard so that his real purpose as private investigator is not discovered by the homophobic members of the Wiser family. The intimacy of the journey aboard the Friends of Dorothy helps to blur the lines between work, personal life, and sexuality even further. And, in spite of their antagonism and gender wars, Errall is fiercely loyal to Quant and is credited with helping to save his life at the conclusion of the third novel. Consequently, while the principal 
professional women in the series are shown to possess independence and strength, female masculinity is attributed solely to the lesbian character and all of the women are given subordinate and supporting roles to the gay male hero. Thus, while Bidulka updates and queers the role of the office wife, he uses the women's professions to support Quant's investigations in various ways. Accordingly, he keeps the man on top.

While the majority of Quant's investigations in the series concern male victims and perpetrators, there is a wide variety of female characters in Bidulka's work; some as victims and perpetrators of crime. The most prominent tend to fall into one of three categories: motherly figures, criminals, and masculine women.

As is often the case with genre fiction, most characters who do not evolve throughout a series but make only one or two appearances in a narrative tend to be rather superficial and stereotypical. All of Bidulka's women are heavily steeped in stereotype, including those whose characters he does develop somewhat from novel to novel. Quant's mother becomes one of the most prominent female figures in the series as a secondary narrative line that Bidulka develops is whether or not Kay Quant will eventually leave her home on the farm and come to live with her son. Despite her regular appearance in the novels, however, she remains primarily in the mothering role, cooking and cleaning for her 'sonsyou.' A Ukrainian immigrant, she speaks with a thick accent, which Quant gently mocks. Mary and Marushka, the older lesbian couple who run Colourful Mary's restaurant are also characterized as motherly to Quant; Marushka, another Ukranian immigrant ensures that Quant eats well when he visits. Dottie Blocka, who appears only in Tapas on the Ramblas as Charity Wiser's lesbian partner is a simple caricature of the proverbial grandmother. She is a doddering old woman-the image 
obviously reinforced by her name-and comes completes with an omnipresent pile of knitting in her lap.

The one exception to this is the character of Sereena Orion Smith. Seerena is a recurring character around whom Bidulka builds a second narrative that evolves throughout the series. This narrative is primarily also investigative, providing a secondlevel mystery to the central mystery in each series installment. For the first four books, this secondary narrative is driven by Quant's desire to discover Sereena's true identity. Even though Quant eventually comes to learn about her past, Sereena is fundamentally unknowable to him. This may be a commentary on the part of Bidulka as to the unknowability of the "other" and the complex and unexplored (and unlikely?) relationship between gay men and women. Of course, since this is detective fiction, a little added mystery is not inappropriate either:

Sereena Orion Smith is best described by that song from the early eighties, 'I've Never Been To Me' by Charlene. She is probably forty-something-I don't know, I don't ask. Once a raving beauty, Sereena's past life of drugs, alcohol and allnight partying shows in her roughened face. I have no doubt that indeed she has been 'undressed by kings... and seen some things that a woman ain't s'posed to see.' ... She never boasts of her travels or experiences or the famous people she once knew and is never impressed by anything - like someone who has seen and done it all and knows it ain't so great. (Amuse Bouche 34)

Sereena Orion Smith is a beautiful, larger-than-life woman to whom Quant is drawn both physically and emotionally. She lives next door to him and shares many of his confidences but she does not speak of her past. As the series moves forward, Quant becomes impelled to search for the truth regarding Sereena's real identity because as he works his cases, odd coincidences bring them together and unexpected clues are dropped in his lap. And finally, Sereena's initials, SOS, point to past drama that could put him and 
Sereena in mortal danger. Accordingly, Sereena's enigmatic story is slowly revealed over the duration of the series.

There could be several divergent meanings attached to Bidulka's development of a female character so enduring as Sereena in the mystery series. Quant, clearly, is attracted to beautiful, strong female characters, not unlike many gay men. Sereena's relationship with Quant does, however, also parallel the socio-cultural phenomenon, which in gay speak is termed the "fag hag." The fag hag is stereotypically a single (though not exclusively) straight woman who prefers the company of gay men to straight men and women. Typically, a fag hag and a gay man develop an intimate non-sexual relationship which differs from that of brother and sister, for example, in that it tends to involve a mutual appreciation of queer style and the trappings of gay consumer masculinity as promulgated by the Fab 5 . Indeed, such relationships are culturally and sociologically complex, and as Jane Ward points out in her essay on queer sexism and gay masculinities, gay men's relationships with women are under-explored and undertheorized in the study of masculinities (153). Bidulka's treatment of the relationship between Quant and Sereena is doubly compelling for the reader due to its conjoining of the familiar with mystery. It is an example of how the author uses the mystery of a gay relationship which has yet to be theorized to his advantage so that he can tease readers with the story of Sereena throughout the series.

Although Sereena is finally revealed to be a victim of male violence in her previous marriage - she killed her husband after he raped and murdered their daughterand the reason for the disappearance of Quant's beloved Uncle Lawrence in Stain of the 
Berry, that is curiously not the end of her story nor of the mystery surrounding her and she returns again prominently in the fifth novel.

In many ways, Sereena was, is and always will be, an alluring mystery to me. And finally, I was okay with that. I did not need to know all of her. In many ways, I preferred not to: it was endlessly more interesting for me. (Sundowner Ubuntu 105)

At times, Sereena is presented as a diva. At the numerous parties and other events she attends with Quant, she is always dressed glamorously to the point of appearing over-thetop. In the scene in which she helps Daniel Guest dress in drag as Clarissa, Bidulka cheekily plays off the similarity in the presentation of the two:

Sereena, her chestnut tresses a cornucopia of curls about her face, was wearing a champagne-coloured pantsuit that seemed to be missing its back, perilously high heels and a stunning collection of garnet jewellery. The other woman [Daniel/Clarissa], whom I did not know, had straight Titian hair that covered her right eye à la Veronica Lake (and sometimes Nicole Kidman) and also wore a pantsuit, but of black silk (its back intact) and a black scarf dramatically woven about her neck. She was laden with diamonds that looked spectacularly real and her lipstick was a vivid red. (Flight of Aquavit 212)

Both "women" are linked through coordinating pantsuits and the use of the sexual colour red. Quant's gaze rests longer on Daniel/Clarissa as evidenced by the longer description he provides. Moreover, the description of Daniel/Clarissa is further feminized by a comparison to Veronica Lake and Nicole Kidman, which is not the case for Sereena. Bidulka thus questions, albeit momentarily, the essentialist notions of female and woman. Quant clearly believes he is looking at a woman when he gazes upon Daniel/Clarissa. This must consequently call into question Sereena's performance of femininity since Daniel/Clarissa might be performing it better.

The other femme fatale character who appears only in Sundowner Ubuntu, Cassandra Wellness also brings an atmosphere of mystery into Quant's personal life. 
Sereena and Cassandra are positioned in the series as queered versions of the iconic femme fatale. Just as the femme fatale is presented in earlier forms of detective fiction as a mysterious victim or alluring woman, only to reveal a hidden deceit and even criminality that threaten the private dick's survival, so too do Sereena and Cassandra reveal themselves as deceitful, flawed, and in Sereena's case, even criminal women. Although Sereena was reacting in horror to the murder of her daughter, she did indeed murder her husband and the complex consequences of that action caused Quant to lose his gay uncle, who was his primary father figure. Beneath Sereena's attractive mystique lie danger, violence, and the reason for Quant's profound loss and grief over his uncle. Presented as an unexpected travel companion for Quant in South Africa, Cassandra is "sort of a young Kathleen Turner type, very attractive and feminine but outdoorsy too, with shiny tresses of wavy auburn hair that flowed attractively down both shoulders" (Sundowner Ubuntu 111). When Quant meets Cassandra on the plane on the way to Africa, Cassandra appears somewhat larger than life. She exhibits a keen interest in Quant and demonstrates an exceptional readiness to wine and dine him and show him about Cape Town. It is probably not accidental that she is called Cassandra; perhaps Bidulka is playing with the figure from Greek mythology here for Cassandra's intentions are suspect and she is not who she appears to be. In an inverted take on the traditional man-seduces-woman scene, Cassandra shows up at Quant's hotel room with a bottle of champagne and a desire to get intimate with him. Somewhat inebriated, Quant begins to engage with her in a sexual manner. The figure of Cassandra represents a dangerous blurring of the lines of Quant's avowed sexual desire and, therefore, his identity as a gay man. As the mystery series progresses, Quant's identity as a "straight-acting" gay man 
who struggles with the competing interests of hegemonic masculinity and gay consumer masculinity is further revealed and affirmed. As an out gay man who has entered into a relationship with another conventionally masculine man, the notion that he could be bisexual or polyamorous troubles his gender identity in ways that would further threaten his identity. Accordingly, Quant ends the romantic interlude prematurely. Cassandra's avid interest in Quant is then revealed to be part of a deceitful plan she concocted: she is not a famous photojournalist but rather a frustrated American housewife on an overseas adventure looking for an affair.

Similarly, Cheryl Guest, Daniel's wife and one of the few other attractive heterosexual women in the series turns out to have a hidden temper and a hidden agenda: she masterminds the blackmail of her husband and orchestrates the attempted murder of Quant and Jared by stranding them in the prairie during a blizzard. Otherwise Bidulka presents women as motherly, bland, or masculine. While there are other female characters, they tend to be presented for the most part in a negative light.

For the most part, Bidulka constructs female masculinity in the series as a characteristic particular to lesbians. These women tend to have less happy fates than heterosexual women. They have stereotypical masculine jobs, like Charity Wiser, who is the head of a meat packing firm, and Captain Bagnato, the captain of the ship Friends of Dorothy. Charity Wiser is furthermore endowed with a very mean-spirited personality, and enjoys ridiculing others to a degree that can only be described as schadenfreude. The lesbian characters are also victims: Kelly Doell is diagnosed with breast cancer and undergoes treatment but the experience is overwhelming for her; she breaks up with Errall and leaves town. Lesbian lovers Moxie Banyon and Tanya Culinaire are the first to 
fall victim to the boogeyman in Stain of the Berry: Moxie drowns and Tanya falls from her high-rise balcony to her death.

Identifying evil as a feminine principle and seeing its dangerous influence controlled was a significant theme in traditional hard-boiled stories, such as The Maltese Falcon and The Big Sleep (Walton and Jones 216). It is revealing that while Bidulka's writing works to circumscribe, control, and repress the feminine, it also inverts this approach in representing women in such a way that there is a clear attempt to identify and control the threats of lesbian female masculinities.

A vibrant example of the threat, circumscription and subsequent control of female masculinity is presented in two short episodes featuring private eye Jane Cross in Flight of Aquavit and Tapas on the Ramblas. In the first instance, the arrival of Jane Cross on the scene is not only a threat to Quant's masculinity but to his life as well. Cross ambushes him in his hotel room, wrestles him to the ground, and begins to interrogate him. Quant quickly realizes that the attacker is a woman and although she has managed to dominate him and sits astride him, "I almost smiled as I thought about her sitting up there slowly coming to the grim realization that she was a dachshund trying to take down a St. Bernard" (Flight of Aquavit 297). Cross soon indicates that she is a private eye from Regina, Saskatchewan, and that she is trailing Quant in regards to a case that she will not discuss. Her manner of speaking and use of language, however, are very revealing of the tensions that Bidulka is playing with in this scene. She speaks colloquially in short authoritative and condescending statements peppered with obscenities. This and her continued reference to Quant as "bub" give a noir feeling to the scene. This atmosphere is 
further amplified by the setting: a hotel room in New York City. Still seemingly in charge of the situation, Cross continues to grill Quant:

'Who's the dame?'

Gawd! Was she channeling Mickey Spillane or something?

'If I answer a question will you answer one?'

'No promises, bub.' (302)

Jane Cross is but a copy of the hard-boiled private dick; the notion that she would be channelling an original hard-boiled author further renders her inauthentic. Cross is a woman performing what was traditionally a masculine occupation and Bidulka foregrounds the blurring of gender lines in this scene:

She tried an Elvis lip curl.

'Is there any store in this goddamned city you didn't go into? You're such a woman.' (300)

The image of the "Elvis lip curl" clearly marks Jane Cross as performing masculinity and doubly reinforces her whole character as a performance: she is a woman performing a man's job performing Elvis performing. Cross then chastises Quant for his extravagant shopping trip across Manhattan. For Jane Cross, Quant's propensity to shop even while on a case calls into question his masculinity; for the reader, it reaffirms his embrace of consumer masculinity. Quant is interpellated as a woman because for Cross, and presumably Bidulka, feminization is a form of ridicule and by feminizing Quant she attempts to maintain her masculine performance as interrogator.

This episode lends support to the notion of tensions created through the competition of traditional masculinity and the contemporary evolution of new gay consumer masculinities theorized by Clarkson and other academics in the study of hegemonic masculinity. Using the trope of the private detective, Bidulka presents a contest between the traditional masculinity of production and aggression, which has 
become a parody of itself along blurred gender lines, and an evolving masculinity based on affluence and the ability to self-consciously consume goods and services. By mocking Cross's performance of masculinity, Quant can discredit her reading of his gay consumer masculinity as feminine. This is an example of how the novel manages readings of masculinity that challenge the versions that Bidulka wishes to privilege.

Quant and Cross go their separate ways antagonistically at the end of their encounter in Flight of Aquavit, with Cross getting the last "abusive" word in. There is no obvious winner in the gender battle at that point. Later, however, it is learned from Cheryl Guest who had hired her, that Cross has been unable to successfully complete her investigation. This further suggests that her performance is always flawed because she is not the real deal.

When Jane Cross resurfaces early on in the following novel, moreover, the threat that she earlier posed to Quant has been further circumscribed and controlled; she has returned to Regina from where she cannot physically harm him. After having been revealed as a failure in her previous investigations Cross now returns in a subordinate and subservient position to Quant: having been offered the job to investigate the threats against Charity Wiser, Cross refuses the case, but suggests that Wiser offer it to Quant. Although she has attempted to effeminize Quant until this point, Cross now re-affirms Quant's masculinity: “I assured her that you weren't the kind of gay man who'd be sashaying up and down the decks in Lycra short-shorts and a feather boa looking for a good time" (Tapas on the Ramblas 28). While it works to further distance Quant from the stereotype of the effeminate gay man, Cross's statement also affirms clearly that Quant is not masquerading as a private eye; he is the real deal. 
The character of Jane Cross also raises issues regarding class. Her colloquial speech peppered with vulgarities, and her propensity for using language similar to that from the hard-boiled pulps, suggest that she is from a working-class background. Her reference to the Rockefeller Center as the 'Rocketfellow Center' also indicates an unworldly quality if not a lack of higher education. Cross is presented in ways that gay men stereotypically view lesbians: masculine, working-class, engaged in a physically demanding job, and dismissive of or unavailable to the consumerist lifestyle. But hers is a singular case: Bidulka presents other lesbians in the series in non-stereotypical situations, including professional (Errall Strane), artistic (Kelly Doell), affluent (Charity Wiser), and motherly (Dottie Blocka). Cross's situation represents one of the few instances in the series where Bidulka provides any glimpse into the lives of people of underprivileged or working classes. This may be because the nature of Cross's work and how Quant comes into contact with her provides one of the few possibilities for Bidulka to construct a character that is not of the middle or upper class. As Rob Cover astutely observes in "Queer with Class":

Working-class people are not in a position to be members of a supposedly diverse community. Lesbian/gay activities are centred on available cash. Drinking, drug use, patronage at clubs and dance parties, and coffee in queer cafés exclude the non-affluent and the working-class poor from participating in the established institutional practices of being queer. (52)

For the most part class goes unmarked in Bidulka's novels and, accordingly, is that of a privileged, white middle-class. Quant himself is comfortably middle-class with upperclass aspirations. Thanks to the inheritance from his uncle, he is able to run his own business, own a large home, and rent a separate office space with a view of the South Saskatchewan River. A simple explanation for the lack of non-affluent and working-class 
characters in the series is that given his affluent, consumer lifestyle and the fact that his clients and friends are middle and upper class, Quant rarely meets individuals who do not participate in his 'community.' A more nuanced argument is unpacked in the fourth chapter. The remainder of this discussion of class will necessarily become further imbricated with issues of ethnicity and race. This is because Bidulka's work predominantly conjoins race and class to signify a threatening form of otherness. Quant's occupational/class trajectory from farm boy with working-class immigrant parents to city police officer to entrepreneurial private eye indicates a substantial upward mobility, as well as movement from a more traditional and circumscribed youth to an adulthood of increased independence and agency. This appears to be a normative construction that reaffirms the North American dream of the immigrant family who through hard work can offer a better life and better opportunities to their children. It also harkens back to the ideal of the loner or outcast from the original hardboiled form and contains a kernel of the wild-west stories that theorists have claimed form the basis for the American hard-boiled. While Quant's Ukranian-Irish immigrant heritage is referenced in the first novel and is insisted upon by the inclusion of his mother as a prominent recurring character, Bidulka attempts to erase this otherness:

I've never considered myself half-Ukrainian. Not because I didn't want to be, but because my mother rarely mentioned the fact and my father, a very proper Irishman, ignored his own heavy brogue and my mother's penchant for garish colour combinations and told us we were Canadians, plain and simple. (Flight of Aquavit 17)

This is a striking move of "ethnic cleansing" by Bidulka that can be interpreted through the lens of class in hard-boiled fiction and in the gay community. In her exploration of the relationship between hard-boiled fiction and the working class, Smith demonstrates 
that these stories acted as a site for the management of working-class men's anxieties regarding their loss of autonomy in the workplace and the loss of white male privilege overall to women and immigrants.

These stories were 'Americanizing' narratives in that they hailed readers as normatively white, implicitly bourgeois, and male. If one were enmeshed in the dense networks of kin and culture that defined ethnic enclaves, hard-boiled detective stories addressed one as a man for whom work was all consuming...Such fiction encouraged a reader to think of himself in unhyphenated 'American' ways, ways that defined selves as autonomous, selfserving individuals. (76)

In Canadian multicultural society which officially purports to value the hyphen, for example, as an expression of linking present to past, the de-hyphenization of Quant's identity would seem brutally "un-Canadian." Smith's theorization suggests, however, that Quant's becoming "Canadian, plain and simple," is a reaffirmation of the image of the autonomous, white middle-class male who continually comes under threat. Rob Cover's work on materialist queer theory and absence also helps us to see Quant's deethnification as a normative move in North American gay and lesbian discourse. Because the essentialist gay identity rests ultimately on the binary of hetero/homo, under the unmarked sign of whiteness, images of ethnicity and class must be excluded (57). In this way, Bidulka interpellates his male readers to identify with Quant as gay, white, and middle class to the exclusion of any other competing identities. This does not exclude the presentation of non-white, non-middle class characters in the novels, but they are always positioned as other and often as outcasts.

While the Russell Quant Mystery Series includes many female characters, as I have demonstrated, its characters are predominantly white and middle class, but this might also imply that the series is ideologically white and middle class. This is especially 
the case for the first three novels. There is a decided departure from this tendency in the fourth and fifth books, however, with the introduction of working-class immigrants, racialized and disabled individuals into the narratives. In particular, the novels present three significant characters who represent the racialized and disabled other. Bidulka's representation of each of these marginalized characters destabilizes gender boundaries. The female figure of 'Grace Jones' is masculinized whereas the two men, Jin Chau and Robin Haywood are feminized. All three of the characters are literally made into monsters who threaten Quant's survival.

The fourth and fifth of Bidulka's Russell Quant novels are the most complex and intriguing in the series. While they are formally complex because of the number of subplots that intertwine with the principal investigational line and because of the number of Canadian and international locations where the stories unfold, there are several complex determinations at work in these texts. Besides providing a continued forum for Bidulka to explore the tensions between masculinities and the threat of the feminine, the fourth and fifth novels openly explore the binaries of white/non-white, civilized/monstrous, able/disabled, and public/private. Through his management of issues of gender, race, and class, Bidulka unwittingly exposes even as he exploits and reinforces the complex workings of heteronormative power relations that subjectify queer bodies within the gay community today.

In this section, then, I am primarily concerned with four characters and the principal investigational narratives of Stain of the Berry and Sundowner Ubuntu. As regards formula, a principal manner in which Stain of the Berry stands apart from the other novels in the series is that apart from short trips to Vancouver and the Arctic, 
Russell Quant's investigation takes place primarily in and around Saskatoon, his hometown. Quant is hired to uncover the truth in the suspicious death of Tanya Culinare, a member of the Pink Gophers queer chorus who apparently fell from her apartment balcony whilst being stalked and frightened by a mysterious figure called the "boogeyman." It is not long before Moxie Banyon, Tanya Culinare's lesbian partner turns up dead in Moose Jaw, and it comes to light that all twelve members of the queer choir group have been or are being targeted by the boogeyman with threats and violence to varying degrees of seriousness. Quant embarks on a systematic search for each of the members of the group (and those who knew the deceased women) in order to learn from their experiences what links each of them has to the mysterious and murderous boogeyman besides their membership in the choir. In keeping with the genre, the question posed by the narrative is: can Russell Quant discover the identity of the boogeyman before another victim is claimed? And, in what cannot be termed a completely unusual turn of events to complicate the narrative, Russell Quant himself falls victim to the boogeyman just before he has the opportunity to unmask the "monster." In Sundowner Ubuntu, on the other hand, Russell Quant's fifth investigational assignment appears much more benign at the novel's outset. Middle-aged and mannish Clara Ridge turns up at Quant's office requesting that the private eye locate her now thirty-something son who disappeared during a troubled adolescence some twenty years earlier. The retainer she offers him is hard to refuse and before he knows it, Quant has embarked on a journey across the Atlantic to South Africa and Botswana in search of a now gay Matthew Ridge (aka Matthew Moxley), volunteering his services as a teacher at various schools in the southern regions of Africa. In a move similar to that in Stain of the 
Berry, Bidulka imagines Quant followed from Saskatoon to Africa by a mysterious monster-like figure with an audible limp who stalks, terrorizes, and physically attacks the people and suspects whom Quant visits and interrogates.

Buried in Stain of the Berry are two characters who raise marked issues of the conjoining of race, class and gender: Grace Jones and Alex Canyon. Bidulka's management of the threat of the racial and ethnic other to Quant's representation of gay, white, middle-class masculinity is worth exploring here. In the first half of Stain of the Berry, Quant finds himself repeatedly stalked and under the surveillance of two disparate figures. On the one hand, there is "a figure in a serious brown suit...standing next to a dark blue Envoy with an Avis car rental sticker on the front bumper" (38). As Quant observes, the only unusual thing about the man was that he appeared to be watching Quant through binoculars. This figure eventually turns out to be Alex Canyon, the security guard of Quant's uncle. Alex is positioned as the most rugged, masculine and handsome man in the series. Alex is also revealed to be gay, and Quant returns Alex's (gay) gaze. Eventually, they become lovers, for according to Bidulka, like attracts like and Quant should only be attracted to other straight-acting gay men. On the other hand, Quant is also stalked by the mysterious figure of Grette Gauntless whom he names Grace Jones. Quant's personal community includes ethnic and non-white individuals in the form of his mother, Marushka from Colourful Mary's, and Marushka's partner Mary Quail who is Cree, while transient characters in the series are exclusively white. Now, Grette Gauntless (Gauntlet?) represents the first non-white intrusion into the Russell Quant community from outside:

There is very little that looks out of place on Davie Street, but a six-foot five, dark Amazon with a nearly bald pate except for a stripe of blue dissecting it into two 
perfect halves, wearing a Janet Jackson circa Rhythm Nation uniform and massive gold hoop earrings - two in each ear and one in her nose-qualifies. She looked like...Grace Jones. (103)

In a not-so-subtle move, Bidulka positions Gauntless as an outsider on Davie Street, one of most diverse streets in Vancouver and located in the heart of the Vancouver gay village. In an incongruous conjoining of masculine body, feminine dress, and pop divalike larger-than-life quality, Bidulka creates a cross-dressing monster-like figure who haunts Quant for a good portion of the narrative. In a highly symbolic scene, where Quant is being tracked by Gauntless, he enters a gay bar with the intention of eluding her. Here Quant cons an older, hyper-masculine and leather-clad bear by pretending that he wants to leave with him for sex. Once out the backdoor, Quant drops the façade, but not without showing a little remorse: "I gave Rufus a big slurpy one on the lips and took off like a jackrabbit" (104). Gauntless's race is conjoined with a hyper-masculinity and hyper-femininity: her gender and sexuality are accordingly unreadable and this blurring of lines makes her an horrific figure. Here one can read the gay bar as symbolic of Quant's community; with the visibly masculine gay man rescuing a feminized Russell Quant, the gender-bending Jones has literally escaped. When she returns, her monstrous qualities have been somewhat tamed: she turns out to be an assistant body guard to Quant's uncle. As such, she is subordinate to hyper-masculine Alex Canyon whom Quant desires sexually.

In Stain of the Berry, the "boogeyman" is a figure who lives both inside and outside the lesbian and gay community. Indeed he is Jinny Chau, a member of the Pink Gophers gay choir. It is significant that Jinny Chau is not introduced by Bidulka until the middle of the novel. This is symbolic of the depth of Jinny Chau's marginalization by the 
novel's ideology. Although he is a member of the Pink Gophers, his marginalized status as non-white, non-masculine, and non-middle-class renders him absent until his otherness is seen as a threat. Of course, it is also likely that his absence is part of a technical device employed by the author to build suspense in the story and forestall audience speculation about the identity of the boogeyman. Given that the initial description of Jinny Chau paints him as so different from the rest of the characters in Stain of the Berry, it is quite possible that readers would immediately suspect him of being the boogeyman; I would suggest that this points up heteronormative discourses at work. Bidulka's description of Jinny Chau is revealing:

Jin Chau was very thin, his shoulders scrawny under a well-worn, pink B.U.M. Equipment T-shirt that just barely reached the top of a pair of waist-squeezingly tight black jeans. He wore no socks and his narrow feet were noticeably paler than his face. At first I thought it was a no sunblock thing...until I looked closer and saw that Jin was wearing makeup; concealer to even out the ochre tones of his elongated face, mascara to make his dark eyes pop, eye shadow, a hint of lipstick and a pinch of pink on high but sallow cheeks. His once black hair (roots were showing) had been dyed red but ended up a faded, pinky-orange hue and was styled into a feathered puff that dominated the crown of his head, reminiscent of the Bay City Rollers. (140)

The initial characterization of Jinny Chau stands in stark contrast to the descriptions of the other gay men presented in the novel. For example, our protagonist, Russell Quant, is described as "six-foot-one, fresh-faced, sandy-haired Adonis" (21). The other gay men in the novel are variously presented as tall, dark or blonde (but not pink!), strong, masculine, sensual and/or sexual. It is clear that there are two principal aspects to the description of Jinny Chau that differ from the characterizations of the other men portrayed in Stain of the Berry. One aspect is Jinny Chau's effeminacy, which is signaled by the description of his body and the clothes and make-up he wears, as well as by his mannerisms and voice, both of which are described subsequently. 
The second important aspect for Jinny Chau is his race. Although the author does not once in the novel explicitly identify Jinny Chau as a gay Asian-Canadian, Bidulka's implied characterizations of the antagonist, arguably stereotypical, are clearly set up to cause the audience to make this judgement. In this way, Jinny Chau becomes doubly different from the rest of the members of the gay community of which he is (a)part.

While Stain of the Berry's boogeyman is revealed to be an effeminate, gay male who has been marginalized by the racism and internalized homophobia of the Saskatoon gay community, the limping 'monster' in Sundowner Ubuntu is finally revealed as an effeminate heterosexual male, Robin Haywood, who had been marginalized, beaten, and consequently disabled as a result of the violent effects of Matthew Ridge's internalized homophobia years prior on a park playground. While this outline relays investigational and overall plot lines rather typical of the detective fiction genre, the majority of the interpellated subjectivities in the novels, in a Canadian context, are also typically reflective of mainstream lesbian and gay communities today.

Similar to Jin's presentation, the character of Robin Haywood is also presented as anathema to the masculine, 'straight-acting' model of men in Sundowner Ubuntu:

Robin Haywood. He was another student at the same school Matthew attended. Apparently Matthew - along with many of the other students - decided he was gay....Robin was a quiet kid, bookish, an easy target for a boy like Matthew...Matthew, the big, sturdy, athletic, girl-magnet was the tormentor, and Robin was his unwilling, long-suffering victim. (245)

In order to highlight the implications of the otherness of Jinny Chau and Robin Haywood, and how this leads them to become the boogeyman and the limping phantom seeking revenge, I want briefly to look more closely at issues of gender, specifically effeminate men, class, and racism in contemporary Western gay communities. 
It has been theorized that gay identity, and indeed the gay community, are relatively new constructions of the Western world. Homosexuality and homosexual identities, as all queer identities, have differed and continue to differ across time and cultures. In centuries past, in Western cultures and elsewhere in the world, what we experience as queer people today could not have been imagined. Eve Kosofsky Sedgwick, arguably one of the founders of contemporary queer theory, maintains that homosexuality was first imagined into being in England in the late nineteenth century. In her first book, Between Men: English Literature and Male Homosocial Desire, she posits that in the West, homosocial bonding in and male domination of a very sexually segregated society led to the fixity of the binary categorizations of heterosexual/homosexual around which social life inescapably turns today. This hetero/homo binary has become naturalized: in order to maintain and reproduce an essentially heterosocial order, male homoerotic feelings have to be avoided. They are ascribed solely to the homosexual.

By the early twentieth century, the social distinction between the male heterosexual and homosexual became more rigid, the latter being seen as effeminate and therefore abject. Quentin Crisp, in The Naked Civil Servant, writes of English society's abject view of homosexuals in the early $1900 \mathrm{~s}$.

The men of the twenties searched themselves for vestiges of effeminacy as though for lice. They did not worry about their characters but about their hair and their clothes. Their predicament was that they must never be caught worrying about either. (21)

Men worked very hard to avoid being seen as effeminate in any way, out of fear that they would be considered homosexual. For the question then was, and in some perspectives remains today, as Jeffrey Escoffier points out in his comments on camp in American Homo: Community and Perversity, "Is a man attracted to another really a woman" (147)? 
Perhaps in part as an attempt to attract men of a similar "perversion," perhaps partially through a desire to regard their perceived and internalized abjectness with some form of humour, some gay men adopted camp in the late 1920s:

The whole set of stylizations that are known as "camp"... was, in 1926, selfexplanatory. Women moved and gesticulated in this way. Homosexuals wished for obvious reasons to copy them. The strange thing about "camp" is that it has become fossilized. The mannerisms have never changed. If I were now to see a woman sitting with her knees clamped together, one hand on her hip and the other lightly touching her back hair, I should think, "Either she scored her last social triumph in 1926 or it is a man in drag. (Crisp 21)

Further analysis there could help to theorize how this abject set of stylizations has been preserved within the gay community and how it comes back to haunt gay men like Russell Quant who would fearfully check themselves for the 'lice' of effeminacy and with trepidation ask, "I'm not macho?" (Stain of the Berry 94). Indeed, as evidenced in contemporary western gay communities, camp is still employed today, and in many of the same ways as it was some eighty years ago. Bidulka clearly presents Jinny Chau in a camp role that repels Quant when they first meet:

'I'm Russell Quant,' I told him, feeling rather unglamorous.

'Yeeeesssssss, you are,' he purred, placing a hand on a hip in a gesture that was meant to be sexy. I noticed his nails were long and shone with clear polish and he wore a multitude of rings. 'What can I doooooooooo for yooooouuuuuuu.' (140)

If camp is abject, and I contend that it is in both hetero-dominant society and within the straight-acting segment of the mainstream gay community, then Jinny Chau's hand-onhip posture in his initial encounter with Russell Quant not only harkens back to Quentin Crisp's observations, it also renders Jinny Chau abject through his performance of camp stylizations that he means to be sexy but which are rejected by Quant. Julia Kristeva's theorization of the abject in Powers of Horror is helpful here in that it explains how the abject is "what disturbs identity, system, order. What does not respect borders, positions, 
rules" (4). In much the same way as Grace Jones/Grette Gauntless, Jinny Chau troubles the boundaries of gender, race, class and sexuality. Accordingly they represent a significant threat to the symbolic order and are abjected by it and, consequently by Quant, who represents through his role as private eye, one whose job it is to restore the symbolic order. According to Kristeva's model, Jinny Chau is radically excluded from the community - indeed, he is kept by his parents in a west-end apartment owned by his uncle because no one wants to live with him-and as a representative of the abject, his flirtation with Quant draws Quant close to that boundary where all meaning collapses (2). Jinny Chau's character is also constructed through camp and transvestism which trouble the boundaries of an essentialist view of genders and sex. As an avowal of performance, Jinny's use of camp acknowledges the awareness or at least the suspicion on the part of the actor that her or his gender could be modified through performance. It is a knowledge encrypted in camp's set of stylizations. In her essay entitled "Performative Acts and Gender Constitution: An essay in phenomenology and feminist theory," Judith Butler refers to camp, drag and transvestism as she theorizes that gender is not an essential state that pre-exists the individual, rather, gender is performed:

Gender is in no way a stable identity or locus of agency from which various acts proceed; rather it is an identity tenuously constituted in time - an identity instituted through a stylized repetition of acts. Further, gender is instituted through the stylization of the body and, hence, must be understood as the mundane way in which bodily gestures, movements, and enactments of various kinds constitute the illusion of an abiding gendered self. (392)

There are different theories about how individuals learn or do not learn to perform various gender roles. But most of these theories, even those outside the realms of queer theory, acknowledge the copying and repeated performance of roles associated with 
different genders. ${ }^{5}$ The majority of gender performance, such as demonstrated through Jinny Chau's effeminacy, might possibly be unconscious or seemingly unalterable. On the other hand, clothing choice, make-up and certain gestures might well point to a more conscious performance. This is significant here because if gender is indeed performed rather than inherent, then accordingly, all of us should have the agency to conform our gender displays to those that are sanctioned overall. This is not the case, however, and as Butler posits, there is no a priori self who performs, rather it is through the complex dynamics of entering into discourse and performativity that one's subjectivity is instantiated. Moreover:

Performing one's gender wrong initiates a set of punishments both obvious and indirect, and performing it well provides the reassurance that there is an essentialism of gender identity after all. (399)

The fact that society punishes those who perform poorly should make it obvious that we know on some level that there is no ontological imperative to gender, that it is indeed socially constructed, performed and supervised. Nonetheless, as the stories of Jinny Chin and Robin Haywood point out, in a society that continues to value masculinity over femininity, an overtly effeminate male is subject to marginalization and oppression, within the gay community as well as without. I see this as a case of men performing badly, perhaps more so when they are not white and of middle-class means. One can ask why this would occur in a community whose core beliefs are supposed to embrace diversity.

The question concerning the perceived femininity of men who desire other men continues to haunt the gay community. Heteronormalizing forces mean that it is

\footnotetext{
${ }^{5}$ For example, see: Reinisch, June M. The Kinsey Institute New Report on Sex: What You Must Know to be Sexually Literate. New York: St. Martin's Press, 1990, pages 244 ff.
} 
imperative to show that men who want men are indeed men. Eve Kosofsky Sedgwick takes up this issue wonderfully in her chapter entitled, "How to Bring your Kids up Gay" in Tendencies:

Indeed the gay movement has never been quick to attend to issues concerning effeminate boys. There is a discreditable reason for this in the marginal or stigmatized position to which even adult men who are effeminate have often been relegated in the movement. A more understandable reason than effeminophobia, however, is the conceptual need of the gay movement to interrupt a long tradition of viewing gender and sexuality as continuous and collapsible categories-a tradition of assuming that anyone, male or female, who desires a man, must by definition be feminine. (157)

Accordingly, effeminate boys and men like Jinny Chau and Robin Haywood and all other fictional or real individuals who are thus perceived have to be repressed or secretized. Men publicly affirming and embracing their effeminacy only help to further destabilize arguments for the separation of sexuality and gender.

Of course, Jinny Chau does not become the boogeyman overnight. Although Bidulka makes few ostensible judgments regarding his characters, he does use Russell Quant's quiet reflections to infer certain "truths." Accordingly, it is implied that Jinny Chau has long suffered from marginalization and oppression: "Something told me Jin Chau had had many fearful boogeymen of his own to deal with in his lifetime" (284). Jinny does not appear to be employed. His parents refuse to let him live with them, rather they pay to have him ensconced in a small apartment in his uncle's building in the Pacific Heights section of west Saskatoon. This is one of the poorer, yet also one of the whiter neighbourhoods in the city. It is far from the centre of the city where more ethnically and sexually diverse people would be more likely to congregate. It is assumed that he has long been the object of disdain because of his looks and his mannerisms and his way of speaking. His use of sarcasm and cynical outlook reinforce this. 
The image of a visibly and sexually deviant Jinny entombed in his family's apartment in a community where he is clearly other recalls the haunting of the 'other'. In her essay on racism in Canada, entitled 'On the Dark Side of the Nation', Himani Bannerji writes about the marginalization of non-white immigrants to and citizens of Canada:

We cannot be successfully ingested, or assimilated, or made to vanish from where we are not wanted. We remain an ambiguous presence, our existence a question mark on the side of the nation, with the potential to disclose much about the political unconscious and the consciousness of Canada as an 'imagined community.' (3)

This notion of an unassimilateable and ambiguous presence that questions the legitimacy of an "imagined community" helps one theorize Jinny Chau's ambiguous role in Stain of the Berry. Publicly ridiculed as an effeminate, gay Asian male, Jinny Chau cannot be accepted and assimilated into the normal gender and ethnic roles of his family, or into the white, masculinist gay community of Saskatoon. Living separately but at the same time together with his family and visiting the gay community at least once a week to for choir practice with the Pink Gophers, Jinny lives both within and between. As he moves between the gay community and his family or ethnic community, he becomes publicly that question mark that Bannerji speaks of, a question mark that forces the interrogation of the racial, economic, gender and sexual power relations that shape each of those imagined communities and draw borders between them.

In Stain of the Berry, what causes Jinny Chau to move from a marginalized gay Asian man in the Saskatoon gay community to becoming the boogeyman occurs on a trip to Regina with the Pink Gophers, where they compete at a music festival. What begins as a seemingly innocent game of "Tequila pigs" soon turns into a scene where Jinny Chau is 
ridiculed, mocked and shunned by the Pink Gophers. While Bidulka provides no obvious justification for this, racism and internalized homophobia are implied. In recounting how Jinny Chau became the boogeyman, Russell Quant explains:

Maybe to a regular person their actions wouldn't have seemed as devastating, but to someone like Jin, a damaged soul, someone who lived his life in constant defense of who he was and couldn't help being it was, simply, the final straw that broke the camel's back. (281)

He became their boogeyman. In his mind, this seemed a fitting sentence for those who'd made his life so miserable...really none of the Pink Gophers-were specifically to blame for the greater woes of life as lived by Jin, but they were handy scapegoats. (283)

Bidulka does not make it clearly explicit in Stain of the Berry why Jinny Chau chooses to take on the form of the boogeyman, why he chooses to hunt down and scare his victims. I argue that Jinny Chau's evolution into the boogeyman signifies that he is no longer performing the role of Bannerji's question mark on the face of the gay community. Rather Jinny Chau has become the exclamation mark that rips into the side of the gay community, exposing its abject racism, masculinism, misogyny, and internalized homophobia.

Accordingly, people begin to get hurt and the integrity of the community is threatened. Both Tanya Culinare and Moxie Banyon die. As the only sexual partners in the group, their destruction could signify the coming apart of the fundamental basis for the community: same sex relationships. Before Russell Quant can bring about the unmasking of the boogeyman and put a stop to his violent attacks, Quant's best friend Jared, a former male model and member of the Pink Gophers, is attacked with acid. Jinny Chau, who declared his love for Jared at the "Tequila pigs" party and was ridiculed, 
tracks Jared to his condo, and throws acid into his face. Russell Quant recounts the events of the tragedy and offers an interesting perspective on Jinny Chau's motives:

Jin did not have the physical strength to physically kill Jared, so he did what came to mind. He destroyed the object of his affection: Jared's beautiful face. (284)

Jared's beautiful, white, tanned, masculine, model face may be read as the face of the oppressor, symbolizing all the white, racist, masculinist, colonialistic determinations that have entombed him in that place of ambivalence that Bannerji writes about, neither in community, nor fully outside of it, hanging rather by crook of question mark: how can I belong?

When along comes Russell Quant, trouble-maker ... getting too close for comfort, and another one of those unattainable kind of gay guys who habitually scorn him. (Stain of the Berry 281)

Racism and sexual racism, masculinism, and internalized homophobia are all body politics. And, the story of Jinny Chau is also about body politics, the right to perform one's body as one chooses, and to have that body included in community with others. In Stain of the Berry, however, the metaphorical struggle over bodies becomes a veritable bodily struggle for top.

In the final action scene in the novel, Russell Quant, having come to the realization that Jinny Chau must be the boogeyman, is ambushed in a dark alley in the Hagar's Heath trailer park and knocked to unconsciousness. When he comes to, he finds himself wounded, bound hand and foot, and nauseous. The boogeyman, Jinny Chau sits astride Quant, preparing to rape him. The scene unfolds with Quant in and out of consciousness, listening to Jinny Chau as he expresses his hurt, his oppression and how he intends to take revenge. It is a one-sided conversation, however, as Quant is incapable of entering into dialogue with his assailant. His thoughts are primarily about how to get 
himself out of his predicament. Before Jinny Chau can effectively dominate the "six-footone, fresh-faced, sandy-haired Adonis" (21), a group of Hagar's Heath inhabitants brandishing wiener and marshmallow roasting sticks pulls Quant to safety and subdues the boogeyman until the police arrive.

It is significant that the white, masculine, sexy and gay hero has been rescued by and accordingly sanctioned by the white heterosexual community of Hagar's Heath. This white working-class community strips Jinny Chau of the last remaining power he has to exert over his oppressors. The future of Jinny Chau is imprisonment, entombment as it were, in a "state" where he will not be able to be successfully ingested, or assimilated, or made to vanish from where he is not wanted. 


\title{
Chapter 4:
}

\section{Reading Gay Subjectivity and the "New Homonormativity"}

\author{
I have no fans. You know what I got? Customers. And customers are your friends. \\ Mickey Spillane \\ Maybe only cheap fiction gives us the true measure of reality. \\ Umberto Eco
}

In the last chapter, I explored how Bidulka writes in a predominantly normative fashion in his representation of gender, class, and race throughout the Russell Quant Mystery Series. In this chapter, I begin with a comparison of the subjectivity of Anthony Bidulka and that of his hero Russell Quant and the author's blurring of the lines between reality and fiction in the creation of the series. I then explore how Bidulka's reality-based representations of the gay community in fact constitute a site where processes of homonormalizing that have been working to construct the mainstream gay community over the course of the last thirty years are carried out. I end the chapter by drawing some conclusions regarding this study and suggest possibilities for future research.

In an article he wrote for the March 2007 edition of Outlooks, a Calgary-based news magazine for "Canada's Gay Community," Anthony Bidulka speaks candidly about his life prior to and after becoming a published and successful writer of gay mystery fiction. He is especially frank about how he was inspired to create his hero Russell Quant. Once he firmly established that he would follow his dream of becoming a full-time writer, Bidulka quit his job as a certified accountant with the well known firm Ernst \& Young, and contemplated the possible subject of his work: 
It was about then that another age-old rule of writing came to me: Write what you know. What did I know? I thought to myself: Well, I know about mysteries (having loved them in every form since I was a child), I know about travel, I know about being gay, I know about Canada, I know about the prairies, I know a little about humour. I got it! I'd write a mystery novel featuring the first — and probably onlyhalf-Ukrainian, half-Irish, gay, ex-cop, ex-farm boy, travelling, Canadian, prairie detective. (16)

This is a most telling admission that speaks to the experience and perceptions of Bidulka as author. It reveals much about his subjectivity, as well as that of his protagonist, Russell Quant, not only through what he says but through his silences as well. It is also revealing about the gay community that he writes for. Bidulka's objective is to write what he knows about being gay, about Canada, about the prairies, about travel, and he lists these areas of experience in order to convince the reader that he has amassed the knowledge to write convincing gay Canadian detective fiction. In doing so, Bidulka glosses over his gender, his race, and his class. In the context of the gay publication Outlooks, and I contend this is the case in most public spaces for the gay community in Canada, Bidulka can be silent about his whiteness, his maleness, and his very comfortable middle-class economic status and at the same time position himself as a typical gay Canadian who knows what being gay means.

Ian Barnard, in his introduction to Queer Race, where among other objectives he sets out a relational framework for theorizing the racialization of queer, observes that all politics, and hence any gay or queer politics, is necessarily "a white-centred and whitedominated politics, since only white people in this society can afford to see their race as unmarked, as an irrelevant or subordinate category of analysis" (4). Accordingly, if Bidulka is to write what he knows, he must necessarily write from the experience of a white, masculinist, affluent gay man from central Canada. Although he might be 
unconscious of it, he is necessarily writing to and for an audience of gay Canadians who share a similar subjectivity: out, gay, male, middle-class, able consumers.

Accordingly, the subjectivity of Bidulka's gay private eye, Russell Quant, is likewise interpellated through the dominant discourses in which Bidulka's own subjectivity is created as an author. This is further borne out in the rest of the article in Outlooks and in an interview with Bidulka published in Fab, a Toronto-based "Gay Scene" magazine, in November 2007, where similarities between the author and his fictional-I would argue semi-autobiographical—creation become apparent. Both author and fictional hero have a penchant for fashionable clothes, international travel, cocktails, fine dining and other first-world indulgences that gay men with good taste and appropriate means are disciplined to embrace.

But this blurring of the lines between the "real" Anthony Bidulka and the fictional Russell Quant is not restricted to the half-dozen interviews that the author has given. From the books themselves to Bidulka's extensive and rapidly growing website dedicated to the Russell Quant Mystery Series, all signs point to a shared subjectivity between the author and the private eye. The back cover of each of the novels, for example, features a photo of Bidulka, an attractive, ruggedly masculine, blue-eyed blond who very clearly resembles the "sandy-haired adonis" (Stain of the Berry 21) who Russell Quant is described as by his friend Anthony. Moreover, the colourful photo on the back of the Flight of Aquavit has Bidulka positioned on the deck of the Silver Whisper cruise ship in September 2002 as it was departing the port at Barcelona. Bidulka is pictured leaning against a deck railing with the harbour behind him and a glass of champagne in hand. One easily imagines the photo of Bidulka doubling as an image of Russell Quant and as 
an illustrative link between that novel, which uses a bottle of Aquavit as a symbol for new life, and the third book Tapas on the Ramblas, which takes place on a cruise ship in the Mediterranean. The fifth book has on its back cover a picture of Bidulka dressed in a safari hat and short-sleeved shirt standing atop Mmamagwa Hill in Botswana. Bidulka notes on his website that he has paid a great deal of attention to the production and selection of author photos on his novels. Accordingly, one reads an intentional desire on the part of the author to link his image to Russell Quant's travels through the African subcontinent in Sundowner Ubuntu.

The linking of an author's image to his or her books is not a new idea, especially not in the pulps and hard-boiled fiction that were intensely marketed often using enticing illustrations and advertisements for products related to the construction and maintenance of hegemonic masculinity. The image of Mickey Spillane, for example, was long associated with his hard-boiled private eye Mike Hammer due to the use of Spillane's image in multiple forms of media used to sell his books. Among the tactics used to market hegemonic masculinity was Spillane's well-known series of Miller beer commercials which helped solidify the author's image as a masculine, beer-drinking, working-class man.

Linda Mizejewski addresses this issue in Hardboiled and High Heeled: The Woman Detective in Popular Culture. In her analysis, Mizejewski finds both Sue Grafton and Patricia Cornwell to be highly superior to other authors of detective fiction in their "orchestrated picturing of their lives as the "real" women behind the fantasy characters" (25). She argues that in Grafton's and Cornwell's media interviews, as well as in various book reviews, "visual and biographical prompts are tied to the "picturing" of the 
investigator-heroine" (29) in such a way that readers are caused to imagine that their heroine might really be like the image they are presented with. Mizejewski likens this tactic to the cinematic use of the body double, where the intent is to create a body more reflective of what is desired. In this case, it is to bring a body to where there is none. Accordingly, large publicity campaigns surround Grafton and Cornwell in order to sell the public figure of the writers as that of their detectives.

Bidulka uses a similar tactic to market his series. The author's own articles and the interviews that he grants are placed in media that primarily serve the gay and lesbian mainstream in Canada, as well as in a few literary journals and detective magazines. The interview in Fab in which Bidulka discusses his love of travel, food, and wine is set among the pages flush with advertisements for travel to Mexico and the Caribbean and fine dining in Calgary and Edmonton. An initial demarcation of the subjectivity of Bidulka's audience is also possible through taking a closer look at the magazines in which he promotes his novels. While both Outlook and Fab purport to target "Canada's gay community" and the "gay scene," their pages are filled with articles, images and advertisements that are clearly aimed at educated, able, affluent, white gay men. The term "gay" in these publications signifies white, and through its refusal to admit the enunciation any discrete identifiers, it reinstalls and reinforces the binary of hetero/homo. This binary is fundamentally necessary to the existence and profitability of these publications.

Bidulka, like Grafton and Cornwell - two authors he lists as having influenced his work- has also developed a heavily promotional website where he publishes not only information about his mystery series, but also copies of his published articles and 
interviews and a large collection of photographs relating to his work as a writer and to his "private" life. Bidulka has travelled to most of the locations that Russell Quant has visited throughout the course of his investigations, so it is not surprising that the website includes photos of these locales. What is revealing is how these images are tagged. Under the category Tapas on the Ramblas is a photo of Bidulka in the Italian countryside captioned: "Visiting Anthony and Jared in Tuscany." Among the photos related to Stain of the Berry, there is one of Bidulka at a berry farm entitled: "Jared surprised me with an outing to the Berry Barn." The reader understands that these are references to the narratives Bidulka has created, yet the photos are positioned as if to offer proof of Quant's verifiable existence as described in the novels. It is as though Bidulka and his alter ego Russell Quant have become one.

This blurring of the lines between the "real" author and the fictional hero is made even more apparent by this year's publication on Bidulka's website of an "Interview with Russell Quant" by Neil Plakcy, American author of the Mahu Mystery Series about a gay homicide detective in Hawaii. In the four-page interview, "Russell Quant" responds to a series of questions about his work and life. His answers represent a blurring of information from the novels and biographical details Bidulka has revealed about himself. Assuredly, while one cannot speak of Russell Quant as a direct representation of the author, the similarity in their biographies is evidence of their shared subjectivity.

While these tactics of lending Russell Quant the face, personality, and biography of the author are part of the marketing campaign used to promote the novels, they are also reflective of Bidulka's desire to make his novels as realistic as possible. The nature of the 
detective genre requires that narratives be grounded in genre conventions. In an interview with Sandra Ruttan of Spinetingler Magazine, Bidulka notes:

I wanted the books to be based in reality, I didn't want people to read them and go, 'That could never happen in Saskatoon.' It's one of the reasons why I don't even consider my books murder mysteries. I consider them mysteries and the mystery can be something other than a violent death. (68)

Accordingly, Bidulka creates realistic situations in his novels first by making gay and lesbian characters the central figures in his series and then by positioning them in normalized situations as citizens who share his subjectivity and that of his target audience. For the narratives to be believable, they must make sense to readers who share or are aware of this subjectivity. The books must be based in "common sense." From the very first pages, the reader learns that Russell Quant is gay and that he is an active part of the Saskatoon gay community which forms the backdrop for the narratives. The victims and the majority of the suspects in Quant's five principal investigations are gay. Most of the recurring characters in the novels are lesbian or gay, including Anthony and Jared, Quant's best friends; Errall and Kelly, the primary lesbian couple with whom he is friends; and, Mary and Marushka, operators of a local restaurant. Only Quant's mother Kay, police detective Darren Kirsch, with whom Quant collaborates occasionally, and Sereena the enigmatic neighbour, are not gay. Indeed, the world of Russell Quant is populated mostly by white gay men (and a few lesbians) who go about their daily lives ordinarily as any other white folk might do. This is why there are gay marriages, gay cruises, gay restaurants, and gay choirs in Bidulka's narratives. Most importantly, as the dominant group in the series, the individuals who form Russell Quant's permanent community are not controversial and do not take part in political activities: there are no leathermen or drag kings among his friends, there are no gay pride parades, and no one is 
living with AIDS in the mainstream gay community of the Saskatoon that Bidulka imagines. Those threats to normalcy come from beyond the unmarked white gay community.

In American Homo: Community and Perversity, Jeffrey Escoffier sets out the trajectory of the contemporary gay project of normalization and underscores how it represents a double-edged sword for the gay community. At their most general, movements that work to normalize gays and lesbians seek to transform the sexual outlaw or pervert into a citizen with rights and obligations like the majority. This presents challenges to the majority as well as to the sexual minority. While the perversity of homosexuality opposes hegemonic values regarding sexuality and gender, normalization also challenges the gay community in that it threatens the pervert and/or outlaw status that helped gays and lesbians recognize each other and form liaisons and communities in the first place. Accordingly, there is the attraction of acceptance on the one hand and the draw of diversity on the other. Just as normalization offers rights such as legislation against discrimination based on sexual orientation and same-sex marriage, it also further prescribes codes of acceptable behaviour and circumscribes gay and lesbian agency. As Escoffier observes, "the normative expectation is that the gay man as sexual outlaw must give up his public sex in the park in order to become the sexual citizen who qualifies for the right to serve openly in the military" (226). Any normalizing project, therefore, functions with a disciplinary effect that helps to form the identities, political, economic and otherwise of citizens. Indeed, Escoffier suggests that corporate marketing and the commodification of gay culture are also normalizing projects that function in the same ways. Here, too, normalization regulates and disciplines: "It represents an improvement 
in some aspects by offering new goods and services-but it also shapes the psychological and physical need that those goods satisfy" (226). Products and services that are not marketed and offered are not valued; they become marginalized. Hence, as Escoffier observes, gay citizens who behave appropriately are assured the protection of some rights and access to a market that further normalizes and regulates on one hand and oppresses and marginalizes on the other. While Escoffier acknowledges that it is not possible to live outside a dominant society with its inevitable norms, he is optimistic that gays and lesbians can continue to bring about social change through the triad of community, direct action, and alliances with other groups.

In an article published in 2002, Lisa Duggan further explores the repercussions of normalizing projects in terms of developing tendencies on the American political front. In this less hopeful article, Duggan analyzes the forging of a new gay mainstream in the United States and introduced the term "homonormativity," which she defines as:

a politics that does not contest dominant heteronormative assumptions and institutions but upholds and sustains them while promising the possibility of a demobilized gay constituency and a privatized, depoliticized gay culture anchored in domesticity and consumption. (179)

Homonormativity opposes both radically conservative claims that gays and lesbians represent a threat to society and the State, as well as progressive calls for queers to work for radical change to the hegemonic heteronormative system. It represents in effect an unhappy "third way," an ambivalent position that only stands opposed to certain forms of oppression - mainly homophobic attacks against the gay, white majority-while actively assimilating into a white heterosexual mainstream dominated by corporate capitalism and the marketing of appearance and behaviour. 
The politics of homonormativity and the management of difference represented in the Russell Quant Mystery Series are laid out from the beginning of the first book. There is perhaps no more direct exposition of the author's politics in this regard, than Anthony Gatt's explanation to Quant as to how he and his partner Jared fit into the dominant culture of Saskatoon:

Although neither admits it, I believe Anthony and Jared do more for allaying homophobia in Saskatoon than a thousand gay pride parades. They do it not by raising placards or pushing their lifestyle into people's faces, but by simply being there, existing with the 'normal' crowd and fitting in perfectly. Often, by the time anyone gets around to discussing the possibility that they might be a couple of homosexuals, it just doesn't matter anymore. (Amuse Bouche 119)

This normalization is justified, according to Quant, by its apparent effect of mitigating homophobia. Bidulka is suggesting here that a solution to homophobia is not to fight for equal rights but rather to assimilate into the "normal crowd." Once again, this insists on the ability to "pass" for heterosexual. Those who cannot pass are excluded from the larger community.

Furthermore, Quant does not out himself by any direct means in the novels. The reader may even find him/herself several pages or chapters into the books before it is clearly apparent that Quant is a gay man. His coming out happens subtly, like Hansen for example, through use of the gaze; Quant is eyeing another man. The reader suddenly finds himself identifying with and taking part in a gay gaze: the subject with whom he or she has identified is objectifying another man through this look and is, likewise, being objectified by the other male character. Additionally, the normalizing process turns around the issue of moral respectability:

Our connection to and success in the straight world is a tenuous one at best. We succeed at it because we play by their rules most of the time. Or at least we make them believe we are. We can escort a man to ritzy social events, refer to ourselves 
as 'we' and 'us,' make no excuses for leaving at the same time, and hold our heads high-just as long as we remain scandal free. But, one nasty homosexual imbroglio and we lose more ground than for a thousand straight divorces. And that's our story. (Amuse Bouche 142)

Bidulka's gays and lesbians must maintain a normative respectability. One is again reminded of Foucault's panopticism: gays and lesbians are disciplined to scrutinize themselves and police their actions themselves so that their appearances and performances remain within boundaries acceptable to dominant culture. This is illustrated further through Quant's various attempts to ensure that he appears manly enough to "pass" and his constant need to reassure himself of his masculinity. Quant regularly attends the YWCA where he works out to keep in shape. He also derives security from having his straight-acting masculinity confirmed by the acknowledgment that he is sometimes "the hunkiest guy there" (Amuse Bouche 229). The panoptic notion is also clearly underscored by Anthony's disciplinary role in the narratives. As gay clothier, Anthony functions by both selling cultural commodities and policing their use in the gay community:

Anthony is my unofficial liaison to the gay world. He knows what we're wearing, what we're drinking, what celebrities we're building up and which, sadly, we're tearing down, what sun-drenched holiday spots are hot, which ones are not and, most of all, he knows who is, who isn't and which of the aforementioned are sleeping together. I, on the other hand, had to be told to stop styling my hair in the George Clooney/ER/Caesar fringe. (Flight of Aquavit 98)

In effect, Anthony takes on the role of a Queer Eye expert in the style of the Fab 5. Like the Fab 5, Anthony is the gatekeeper to gay consumer masculinity. He also acts like a deputy to the force of dominant culture, ensuring that accepted gay members continue to pass. In completing this metaphor, Quant positions himself both inside and outside the gay community and in league with the straight guy, who needs instruction, coaching and 
discipline in what to wear and how to wear it in order to embrace more fully a socially accepted version of gay consumer masculinity.

Significantly, it is not only appearance that is policed and controlled under homonormativity. In her review of Stain of the Berry in Spinetingler Magazine, Sandra Ruttan observes:

This book is not filled with descriptive sex scenes-in fact, there's little sex at all and it is primarily off camera-so I hope people won't confuse my point. I have read other stories where sexual orientation was a critical factor of the plot and the protagonist was gay, but I have never read one where the majority of the characters were openly gay. As a result there is always the sense throughout the storyline that the issue of sexuality is very important. It is a central theme to the book. (77)

I would argue that while sexuality is an important, even central theme to the series, the sex act itself is not. An ironic side effect of Bidulka's normalizing project is the erasure of homosexual sex in his novels. In the first novel, Quant does not engage in sex with the Catholic priest despite the drawn out dance of desire that unfolds in the last half of the book. A final page of striptease at the end of the novel reveals only that a sexual encounter "might" take place between Quant and another man outside the confines of the narrative, only if the reader imagines it. At the beginning of Flight of Aquavit, what appears to be a hot cruising and a pick-up scene turns out to be something completely different and sees Quant fleeing the scene to save his life, while sex between Quant and James later in the narrative is reduced to some aural masturbation over the telephone, again, only if imagined by the reader. Finally, once Quant is involved in a relationship with Alex Canyon, a potential sex scene between the two in Quant's car ends prematurely. Quant forgets to the turn the car off after he has parked it in his garage, so due to an influx of carbon monoxide, the sex act becomes poisoned. Effectively, the possibilities 
for "immoral" sex acts with a priest and as a result of cruising in the outdoors are disciplined out of the narrative. Sex is returned to the privacy of the bedroom beyond the prying eye of reader. The homosexual outlaw in Quant is quarantined.

Homonormativity, then, underscores the importance of "passing" and how the homosexual outlaw who is so morally antithetical to the heteronormative system can be accepted, so long as he is white and middle-class. Eva Mackey's exploration and analysis of the ways "dominant culture" functions to maintain its hegemonic position in Canada are also very useful in helping to explain further homonormative processes and the concomitant development and self-maintenance of a gay "dominant culture" within the dominant heteronormative culture. In her significant book, The House of Difference, Mackey reads a variety of Southern Ontario community festivals with her own queer(ying) eye to elucidate the various ways in which "dominant culture" reveals itself through its management and repression of differences. She analyses various aspects of these cultural events, including policy frameworks and promotional activities, the performances themselves, and interviews with community members.

Difference is not allowed if it threatens the imagined community's non-political gemeinschaft. Repeatedly, people who embody forms of political difference perceived to threaten community consensus, are cast outside of the boundaries of 'community', and nation. Those left inside the 'community'...may feel pride in the supposedly natural and authentic solidarity and consensus that remain in the community. (134)

Mackey posits a "construction of innocence" that occurs within the dominant community such that the attitudes and behaviours of the majority just make "common sense" in the Foucaultian use of the term. The community's attempts at inclusion of minorities, so long as this inclusion is not politicized, actually reveal colonialist, racist, and paternalistic attitudes and the continued whitening of the community. The suggestion that the 
"dominant culture" is guilty of these attitudes is, however, met with disdain since their embrace of difference is innocent of controversy. In the examples of Anthony and Jared cited above, the two gay men are not threats to the dominant community so long as they do not act politically or create scandal.

Both Bidulka and Quant struggle to maintain a part of traditional social forms while at the same time attempting to negotiate and accept difference: for example, Bidulka begins to queer aspects of the hardboiled subgenre yet maintains overall the form and its morality; Quant claims an affinity with straight-acting hegemonic masculinity but is compelled to accept the market's version of gay consumer masculinity, as well. Moreover, Bidulka's subjectivity reveals him to be, like his hero, negotiating space within the dominant culture—as a gay, white man who passes well enough to blend in with the "normal" people—and outside it as a member of community who advocates diversity and on behalf of sexual outlaws. In a couple of instances during his interview with Sandra Ruttan, Bidulka further reveals the tensions he faces in mapping difference in his construction of the Saskatoon gay community. At the same time, he also reveals himself as part of the "dominant culture" that Mackey explores, and consequently presents colonialist, racist, and paternalistic attitudes toward those who embody difference that contests the dominance of the white middle class.

In the first instance Bidulka is explaining how he goes about putting together the three outlines he prepares for each book. The sense of place is very important to Bidulka and his audience, and he has learned that realistic locations are necessary for a believable narrative. Accordingly, Saskatoon is like a character to him:

In this fourth book, I was at a book club meeting in Saskatoon and there's a couple scenes in the book that take place in a trailer park within Saskatoon city 
limits and people were just so excited about it because they had no idea that was there. People have actually gotten in their cars and driven there to take a look because it is kind of an oddity. That's part of the reason I wrote about it. About two years ago I came across it, just by turning the wrong way down a street, I ended up in this kind of No Man's Land, something that looked like nothing else in our city, and there it was and had been for decades. (Ruttan 66)

(italic mine)

Bidulka's description of the trailer park as being within city limits but also an "oddity" gives it a blurred, liminal quality. At the same time, it does not belong within the acceptable community. You get there "by turning the wrong way down a street" and it is a "No Man's Land." The treatment by Bidulka and his audience of a trailer park as somehow exotic and somehow uninhabitable by them (an empty border area), draws on the idea of community being built on consensus, where there is pride in similarity and a perceived authenticity. The trailer park is the site that both attracts and disgusts. Bidulka builds the trailer park into the narrative, as well as into his website where a photo of it is captioned: "Where the streets have no name." The trailer park passes quickly from exotic locale to the liminal site of the attempted rape of Quant by the Boogeyman, and is summarily abjected.

In another instance, Ruttan asks about crime in Saskatoon and how Bidulka uses it to develop the criminality in his novels. She raises a specific incident that took place several years earlier where two Saskatoon policemen allegedly transported an Aboriginal youth outside the city limits and left him to die in the cold. Ruttan asks Bidulka how this might have affected his writing.

It does and doesn't ... Certainly our population leans towards aboriginal population and there's a lot of crime amongst aboriginals, the way statistics run, and in our province we're still shifting to that reality and making sure we're doing the right stuff for the aboriginal population, that's really important to me. We need to get smart about that. We have to work together ... But certainly stuff like that is damaging to a community as a whole overall, to have a situation where you 
have allegedly two policemen who have taken an aboriginal youth out and dumped him on the edge of the city. It's horrendous. (67-68)

(italic mine)

These remarks by Bidulka clearly display a colonialist, paternalist and, yes, even racist sentiment. They reiterate discourses of the "dominant culture" about who belongs within community and who is not acceptable. Readers will realize that this real crime is reflected in the survival scene in Stain of the Berry in which Russell Quant and Jared are trucked out beyond Saskatoon city limits and dumped in a field outside town at night in the middle of a blizzard. Only, in Bidulka's whitened version, the Aboriginal has been erased. As the racialized subject of a "horrendous" action, he, too, is abjected. In Bidulka's retelling of the story, Russell Quant and Jared Lowe are brought back into the community and the symbolic order, guided by Detective Kirsch flanked by two Canadian Mounties as a symbol of the law.

In undertaking this research, my general aim has been to explore the various ways in which the gay community is represented in Anthony Bidulka's Russell Quant Mystery Series. This paper affirms that Anthony Bidulka has succeeded in establishing an imagined gay community unlike any other in Canada. His work certainly adds a unique, gay Canadian private eye to a growing and increasingly globalized body of popular fiction that is still undeniably dominated by American and British authors and heterosexual subjectivities.

My specific objectives were to focus on Bidulka's representations of gender, class, and race in the construction of his imagined gay community and how these representations reflect some of the tensions that one experiences in the gay community today. While Bidulka's portrayal of Quant's life in Saskatoon helps to make gay and 
lesbian identities plainly visible and legitimizes some of them, the novels work as agents of homonormativity, as well. I see an important distinction between making lesbian and gay characters visible in genre fiction and rendering the conditions of their visibility homonormative. Queer characters can be presented in all their difference, sexual, cultural, and other, so that their deviance from heteronormative models is not short-circuited by what is presupposed to be normal but is rather fully expressed in all its queerness. Through processes of homonormalization, on the other hand, the powerful, in this case the author, seek to present and reposition lesbians and gays as individuals within the normative confines of a "moralizing" heterosexual society and culture organized around family ties and reproduction. The majority of the characters in the series represent a politics that does not radically oppose nor even resist dominant heteronormative social and cultural organization. Rather, to paraphrase Duggan once more, Bidulka's characters can be read as upholding and furthering heteronormative knowledge and institutions, in the Foucaultian sense, that organize the power relations regulating gender, race, and class in contemporary society.

While Bidulka's books are gay, I contend that they are not queer in a way that radically contests heteronormativity: they re-present the mainstream wave of homonormalization that dominates the gay community in the West today. In his discussion on theorizing the queer, Jeffrey Escoffier explains in American Homo:

Community and Perversity that:

Specifically, queers resist the regime of the normal. It implies that we redefine the problem of homosexual liberation so that we no longer fight intolerance but resist normalization. We need to stand firm against heteronormalization-the domination of norms that support, reinforce, and reproduce heterosexual social norms. (175) 
Reading Bidulka's own words about his work reveals the homonormalizing processes involved in his writing, as well as the racial and colonialistic attitudes of the "dominant culture." It reveals the ambiguity of such a project and how the author, while part of a marginalized group, also shares in the attitudes and behaviours of dominant culture.

The introduction into the detective novel of a gay private eye who has sex with other men, revels in gay culture, discloses his capacity to stumble and fall, and shows an ambivalent sympathy toward the criminals he captures does work somewhat to resist the "normal." Nonetheless, while working within the confines of a heavily formulaic genre, Bidulka cannot escape the normalization imposed by the genre itself and by the homonormalizing forces to which he and his audience are necessarily subjected.

As regards the success of the Russell Quant Mystery Series, the future continues to look rosy pink for Bidulka. While he has decided to take a one-year break from writing the series to pursue work on a different kind of novel, he does intend to launch the next installment of the series in fall 2009. In addition, he has published articles on his website indicating that Toronto's Breakthrough Films, Vérité Films—-the producers of the Canadian sitcom Corner Gas-and CTV are in collaborative development of a thirteenpart Canadian television series based on the Russell Quant Mystery Series. If Russell Quant comes to television, how gay, how queer will Quant be? In a recent article published in the Ottawa Citizen, Paul Gessel points us to a possible answer:

Norman Dahl, a retired editor-translator in Gatineau, is one of Bidulka's biggest fans... and praises the author for not "pushing" a gay agenda. "I would not call them gay novels." And that's the way Bidulka wants his books to be seen. "They are not books about being gay," the author says, "They're books with gay characters.' (3) 
If the Quant television series becomes a reality, it will certainly be interesting to investigate the construction of Bidulka's gay community for TV and how it will differ from the community developed in the novels. A line of serious enquiry could be made into how the perceived subjectivities of the target audience for the television show, which presumably would include a much wider cross-section of the "dominant culture," would inform the presentation of those aspects that I have explored in this paper, from overall themes to tensions between masculinity and femininity, to the management of difference. It would be culturally and socially valuable to explore whether the television series, too, would present a politics of homonormalization that continues to value and normalize images of gay white straight-acting male consumers, while repressing and marginalizing those who present the threat of difference. 


\section{Bibliography}

Adrian, Jack. "Obituary: Joseph Hansen." The Independent. 7 December 2004.

Findarticles.com. CNET Networks. 16 September 2008. <http://findarticles.com>. Keywords: Joseph Hansen Obituary Independent.

Allan, James. "Imagining an Intercultural Nation: A Moment in Canadian Queer Cinema." In a Queer Country: Gay and Lesbian Studies in the Canadian Context. Ed. Terry Goldie. Vancouver: Arsenal Pulp Press, 2001. 138-159.

Bannerji, Himani. "On the Dark Side of the Nation: Politics of Multiculturalism and the State of Canada." Journal of Canadian Studies 33.13 (1996):103-128.

Barnard, I. Queer Race: Cultural Interventions in the Racial Politics of Queer Theory. New York: Peter Lang, 2004.

Baxt, George. A Queer Kind of Umbrella: A Pharoah Love Mystery. New York: Simon and Schuster, 1995.

Bidulka, Anthony. Amuse Bouche. Toronto: Insomniac Press, 2003.

--.. Flight of Aquavit. Toronto: Insomniac Press, 2004.

---. The Russell Quant Mystery Series. Ed. Anthony Bidulka. 2005. 16 September 2008.

$<$ www.anthonybidulka.com>.

---. Stain of the Berry. Toronto: Insomniac Press, 2006.

---. Sundowner Ubuntu. Toronto: Insomniac Press, 2007.

--. Tapas on the Ramblas. Toronto: Insomniac Press, 2005.

---. “Telling a Story." Outlooks March 2007: 16-17.

Breu, Christopher. Hard-boiled Masculinities. Minneapolis: University of Minnesota, 2005.

Bronski, Michael. Culture Clash: The Making of Gay Sensibility. Boston: South End Press, 1984.

Browning, Frank. The Culture of Desire: Paradox and Perversity in Gay Lives Today. New York: Crown Publishers, 1993.

---. A Queer Geography: Journeys Toward a Sexual Self. New York: Crown Publishers, 1996. 
Butler, Judith. Bodies That Matter: On the Discursive Limits of "Sex." New York: Routledge, 1993.

---. Gender Trouble: Feminism and the Subversion of Identity. New York: Routledge, 1990.

---. "Performative Acts and Gender Constitution: An Essay in Phenomenology and Feminist Theory." The Feminism and Visual Culture Reader. Ed. Amelia Jones. New York: Routledge, 2003. 392-402.

Carter, Julian B. The Heart of Whiteness. Durham and London: Duke University Press, 2007.

Castricano, Jody, Cryptomimesis. Montreal and Kingston: McGill-Queen's Press, 2001.

Cavell, Richard and Peter Dickinson. Sexing the Maple: A Canadian Sourcebook. Peterborough: Broadview Press, 2006.

Chandler, Raymond. The Big Sleep. New York: Vintage Crime/Black Lizard, 1992.

---. Farewell, My Lovely. New York: Vintage, 1988.

-.-. The Long Goodbye. New York: Vintage Crime, 1988.

Clarkson, Jay. "Contesting Masculinity's Makeover: Queer Eye, Consumer Masculinity, and 'Straight-Acting' Gays." Journal of Communication Inquiry 29 (2005): 235-255.

Collins, Jim. Uncommon Cultures: Popular Culture and Post-Modernism. New York: Routledge, 1989.

Cook, J. S. A Cold-Blooded Scoundrel: An Inspector Devlin Mystery. St. John's, Newfoundland: Flanker Press, 2005.

Cover, Rob. "Bodies, movements and desires: lesbian/gay subjectivity and the stereotype." Journal of Media \& Cultural Studies (2004): 81-97.

---. "Queer with Class. Absence of Third World Sweatshop in Lesbian/Gay Discourse and a Rearticulation of Materialist Queer Theory." Linked Histories: Postcolonial Studies in a Globalized World. Eds. Pamela McCallum and Wendy Faith. Calgary: University of Calgary Press, 2005. 45-60.

Crime Fiction Canada. Eds. Rose, Marilyn J., Jeannette Sloniowski, and Philippa Gates. 2001. Brock University. 16 September 2008. $<$ https://www.brocku.ca/crimefictioncanada/index.php $>$. 
Crisp, Quentin. The Naked Civil Servant. New York: The New American Library, 1968.

Dagostino, Scott. "Out in Africa. Author Anthony Bidulka and his detective alter-ego circle the globe." Fab 28 November 2007: 24-25.

De Lauretis, Teresa. Technologies of Gender: Essays on Theory, Film and Fiction. Bloomington and Indianapolis: Indiana University Press, 1987.

Dickinson, Peter. Here is Queer: Nationalisms, Sexualities and the Literatures of Canada. Toronto: University of Toronto Press, 1999.

Duggan, Lisa. "The New Homonormativity: The Sexual Politics of Neoliberalism." Materializing Democracy: Toward a Revitalized Cultural Politics. Eds. R. Castronovo and D. Nelson. Durham, NC: Duke University Press, 2002. 175-194.

Escoffier, Jeffrey. American Homo: Community and Perversity. Los Angeles: University of California Press, 1998.

Faludi, Susan. Backlash: The Undeclared War Against American Women. New York: Crown, 1992.

Foucault, Michel. Discipline and Punish: The Birth of the Prison. Trans. Alan Sheridan. New York: Vintage, 1979.

---. The History of Sexuality: Volume One: An Introduction. Trans. R. Hurley. London: Penguin, 1981.

---. Power/Knowledge: Selected Interviews and Other Writings, 1972-1977. Ed. Colin Gordon. New York: Pantheon, 1980.

Garber, M. B. Vested Interests: Cross-Dressing and Cultural Anxiety. New York: Routledge, 1992.

Gessel, Paul. "An unknown Quant-ity. Is Canadian television ready for a series about a gay detective in Saskatoon, with a great wardrobe and two schnauzers?" The Ottawa Citizen 7 November 2007. Canada.com. <http://www.canada.com/ottawacitizen.html>. Keywords: Anthony Bidulka Russell Quant.

Goldie, Terry. Pink Snow: Homotextual Possibilities in Canadian Fiction. Peterborough: Broadview Press, 2003.

---. "Queer Nation." In a Queer Country: Gay and Lesbian Studies in the Canadian Context. Ed. Terry Goldie. Vancouver: Arsenal Pulp Press, 2001. 7-26.

Gosine, Andil. "Pink Greens. EcoQueers Organize in Toronto." Alternatives Journal: Environmental Though, Policy and Action 27.3 (2001): 35-36. 
Greenhill, Pauline. "Can You See the Difference?: Queerying the Nation, Ethnicity, Festival, and Culture in Winnipeg." In a Queer Country: Gay and Lesbian Studies in the Canadian Context. Ed. Terry Goldie. Vancouver: Arsenal Pulp Press, 2001. 103121.

Gunn, Drewey Wayne. The Gay Male Sleuth in Print and Film: A History and Annotated Bibliography. Lanham, Maryland: The Scarecrow Press, 2005.

Hammett, Dashiell. The Maltese Falcon. New York: Vintage, 1992.

---. Red Harvest. New York: Vintage, 1992.

---. The Thin Man. New York: Vintage, 1989.

Hansen, Joseph. Fadeout. New York: Henry Holt and Company, 1970.

---. Nightwork: A Dave Brandstetter Mystery. London: Peter Owen, 1984.

Horkheimer, Max and Theodor W. Adorno. Dialectic of Enlightenment. New York: Continuum, 1972.

Jenkins, Catherine Anne May. "The Hardboiled Outsider: Hardboiled American Fiction as an Existential Literature." MA Thesis. Trent University, 1996.

King, J. L. On the Down Low: A Journey Into the Lives of 'Straight'Black Men Who Sleep with Men. New York: Broadway Books, 2004.

Kinsman, Gary. "Challenging Canadian and Queer Nationalism." In a Queer Country: Gay and Lesbian Studies in the Canadian Context. Ed. Terry Goldie. Vancouver: Arsenal Pulp Press, 2001. 209-234.

--.. The Regulation of Desire: Sexuality in Canada. Montreal: Black Rose Books, 1987.

Kittredge, William and Steven M. Krauzer, Eds. The Great American Detective. New York: Mentor, 1978.

Kristeva, Julia. Powers of Horror: An Essay on Abjection. Trans. Leon S. Roudiez. New York: Columbia University Press, 1982.

Mackey, Eva. The House of Difference: Cultural Politics and National Identity in Canada. Toronto: University of Toronto Press, 2002.

Manthorne, Jackie. Deadly Reunion. Charlottetown: gynergy books, 1995.

---. Final Take. Charlottetown: gynergy books, 1996. 
Markowitz, Judith A. The Gay Detective Novel: Lesbian and Gay Main Characters and Themes in Mystery Fiction. McFarland and Company, 2004.

Miron, Janet. "Here is Queer: Nationalisms, Sexualities, and the Literatures of Canada." Journal of the History of Sexuality 10.2 (April 2001): 316-320.

Mizejewski, Linda. Hardboiled and High Heeled: The Woman Detective in Popular Culture. New York: Routledge, 2004.

Morgan, Jason: "Queerly Canadian: 'Perversion Chic' Cinema and (Queer) Nationalism in English Canada." Canadian Cultural Poesis: Essays on Canadian Culture. Eds. Garry Sherbert, Annie Gerin and Sheila Petty. Waterloo: Wilfrid Laurier University Press, 2006. 211-227.

Mumford, Kevin J. Interzones: Black/White Sex Districts in Chicago and New York in the Early Twentieth Century. New York: Columbia University Press, 1997.

Munt, Sally R. Murder by the Book? Feminism and the Crime Novel. London: Routledge, 1994.

Nava, Michael. The Little Death: A Henry Rios Mystery. Los Angeles: Alyson Books, 1986.

Phillips, Edward O. Buried on Sunday. Toronto: Cormorant Books, 1998.

-... Sunday Best. Toronto: Cormorant Books, 1998.

---. Sunday's Child. Toronto: Cormorant Books, 1998.

---. Working on Sunday. Toronto: Cormorant Books, 1998.

Pigeon, Elaine. "Hosanna! Michel Tremblay's Queering of National Identity." In a Queer Country: Gay and Lesbian Studies in the Canadian Context. Ed. Terry Goldie.

Vancouver: Arsenal Pulp Press, 2001. 27-49.

Plakcy, Neil. "Interview with Russell Quant." The Russell Quant Mystery Series. Ed. Anthony Bidulka. 2005. 16 September 2008. <www.anthonybidulka.com>.

Rand, Lou. The Gay Detective. San Francisco: Cleis Press, 2003.

Ruttan, Sandra. “Anthony Bidulka Interview.” Spinetingler Magazine. Spring 2007. 6477.

Ryan, Garry. The Lucky Elephant Restaurant. Edmonton: NeWest Press, 2006. 
---. The Official Site of Gary Ryan. Ed. Garry Ryan. 2008. 16 September 2008.

$<\mathrm{http} / / /$ www.garryryan.ca $>$.

---. Queen's Park. Edmonton: NeWest Press, 2004.

Sedgwick, Eve Kosofsky. Between Men: English Literature and Male Homosocial Desire. New York: Columbia University Press, 1985.

---. Epistemology of the Closet. Berkeley and Los Angeles: University of California Press, 1990.

---. Tendencies. Durham: Duke University Press, 1993.

Signorile, Michaelangelo. Queer in America: Sex, the Media and the Closets of Power. New York: Doubleday, 1993.

Silverman, Kaja. The Subject of Semiotics. New York and Oxford: Oxford University Press, 1983.

Skene-Melvin, L. David St C. Canadian crime fiction: An annotated comprehensive bibliography of Canadian crime writing from 1817 to 1996 and biographical dictionary of Canadian crime writers, with an introductory essay on the history and development of Canadian crime writing. Shelburne, Ontario: The Battered Silicon Dispatch Box, 1996.

Slide, Anthony. Gay and Lesbian Characters and Themes in Mystery Novels. Jefferson, North Caroline and London: McFarland and Company, 1993.

Smith, Erin A. Hard-Boiled: Working-Class Readers and Pulp Magazines. Philadelphia: Temple University Press, 2000.

Stevenson, Richard. Ice Blues: A Donald Strachey Mystery. New York: St. Martin's Press, 1986.

---. Third Man Out: A Donald Strachey Mystery. New York: St. Martin’s Press, 1992.

Stockton, Kathryn Bond. Beautiful Bottom, Beautiful Shame. Durham and London: Duke University Press, 2006.

Vallance, Tom. "George Baxt: Author of 'outrageous' mystery novels." The Independent. Thursday, 10 July 2003. <http://www.independent.co.uk.html $>$. Keywords: George Baxt Novels.

Walton, Priscilla L. "Murder Ink: Detective Fiction in Canada." Pop Can: Popular Culture in Canada. Eds. Van Luven, Lynne and Priscilla L. Walton. Scarborough: Prentice Hall Allyn and Bacon Canada, 1999. 50-55. 
Walton, Priscilla L. and Manina Jones. Detective Agency: Women Rewriting the Hardboiled Tradition. Berkeley: University of California Press, 1999.

Ward, Jane. "Queer Sexism: Rethinking Gay Men and Masculinity." Gay Masculinities. Ed. Peter Nardi. Thousand Oaks: Sage Publications, 2000. 152-175.

Wheeler, Sharon. "No Justice: The Crime Novels of John Morgan Wilson." Questions of Identity in Detective Fiction. Eds. Linda Martz and Anita Higgre. Newcastle: Cambridge Scholarship Publishing, 2007. 7-17.

Williams, David. Imagined Nations: Reflections on Media in Canadian Fiction. Montreal and Kingston: McGill-Queen's University Press, 2003.

Wilson, John Morgan. Justice at Risk. New York: Bantam Books, 2000.

Zubro, Mark Richard. One Dead Drag Queen: A Tom and Scott Mystery. New York: St. Martin's Press, 2000. 